\title{
Reducible oxides as ultrathin epitaxial films
}

\author{
Paola Luches, Sergio D’Addato
}

\begin{abstract}
This chapter reviews and discusses recent work on two-dimensional films of reducible oxides supported on metal substrates. In general, peculiar chemical and structural phases, different from the bulk ones, can be stabilized depending on the oxygen chemical potential, on kinetic processes and on the specific substrate used. A peculiarity of reducible oxides is that the observed phases can often be reversibly transformed one into the other by applying reducing and oxidizing treatments.
\end{abstract}

\section{Introduction}

An oxide is defined reducible if it can be easily and reversibly reduced depending on the ambient conditions. Reducibility is linked to the existence of two or more oxidation states with comparable stability for the cations. Prototypical reducible oxides are represented by cerium and titanium oxides, although also other transition metal and rare earth oxides can be considered reducible; among these for example other rare earth oxides, like $\mathrm{PrO}_{\mathrm{x}}, \mathrm{SmO}_{\mathrm{x}}, \mathrm{TbO}_{\mathrm{x}}$, and other $3 d$ metal oxides, like $\mathrm{VO}_{\mathrm{x}}, \mathrm{MnO}_{\mathrm{x}}, \mathrm{FeO}_{\mathrm{x}}, \mathrm{CoO}_{\mathrm{x}}$, but also $\mathrm{HfO}_{\mathrm{x}}, \mathrm{TaO}_{\mathrm{x}}, \mathrm{NbO}_{\mathrm{x}}, \mathrm{WO}_{\mathrm{x}}$ and many more.

Indeed, reducibility is very relevant for catalysis, since materials based on reducible oxides can act as oxygen buffers, which can store and release oxygen and/or charge, promoting redox reactions with a unique regeneration ability [1]. Furthermore, reducibility is an important property also in view of the application of oxides in other fields, like for example energy conversion and storage, ${ }^{1}$ biomedicine [2] and memories [3]. Reducibility is not only linked to the material capacity of easily forming oxygen vacancies but also to the reversibility of the process and to oxygen transport properties within the material.

The influence of reduced dimensionality on the reducibility of an oxide is certainly relevant in view of the optimization of the properties of the material through the understanding of the modifications which arise with confinement. Pronounced changes of the electronic structure of oxides at reduced dimensionality have been widely investigated, and interesting properties have been observed on reducible oxides in particular [4,5]. In cerium oxide particles of nanometric size the oxygen vacancy formation energy has been found to be greatly reduced and to reach a minimum at a specific size [4], thereby causing a surprisingly enhanced reactivity of catalysts made of metal nanoparticles supported on nanocrystalline cerium oxide [6], possibly also facilitated by easy oxygen transfer to the supported metal nanoparticles [7].

If only one of the dimensions of the considered material is confined to the nanoscale, i.e. if the system under study is a two-dimensional film, several interesting modifications are introduced and intriguing phenomena can take place. The stabilization of metastable structural phases by epitaxy or by the mere spatial confinement, the presence of lattice strain or rumpling, the interaction with the substrate, in terms of charge transfer but possibly also of interfacial atom exchange, the different 
stability of structural defects, are all expected to determine relevant changes in the electronic structure, which give origin to systems with different properties compared to the corresponding bulk phases.

The studies of two-dimensional reducible oxides are typically carried out on model systems, i.e. on ultrathin films supported on single crystalline substrates, prepared and analyzed in high or ultrahigh vacuum. The investigations aim at identifying interesting aspects on simple systems, which can be analyzed by surface science techniques and understood with the help of theoretical descriptions. A proper modeling of the systems under investigation often represents a crucial step for a complete atomic level understanding of the material properties and potential performances. Only through the fundamental insight of the new properties which arise on simple systems, the much more complex real systems, based on the same materials, can be understood and optimized in their functionality. For example, catalysts made of metallic nanoparticles supported on reducible oxides typically involve some degree of encapsulation of the metal within the oxide and the formation of very thin oxide layers on the metal nanoparticle surface, through the so called strong metal-support interaction (SMSI) [8]. Ultrathin oxide layers exposing different facets, with different structures and morphologies can be prepared in the form of model systems to identify the most active species towards the considered reaction. The results of these studies can be used to design the catalysts with an optimized activity and selectivity by finding suitable synthetic routes to maximize the density of required active sites for the chosen specific functionality.

In this chapter recent studies on the properties of ultrathin films of reducible oxides are reviewed, focusing on the aspects which influence the reducibility of the materials at the two dimensional limit. New properties of cerium oxide two-dimensional films are discussed in section 2. Section 3 reports studies of titanium oxide two-dimensional films, which are interesting for comparison and for complementing the concepts outlined on cerium oxide based systems. Selected studies of ultrathin films of different reducible transition metal and rare earth oxides are finally reported in section 4.

\section{Cerium oxide two-dimensional films}

The most stable cerium oxide phase is $\mathrm{CeO}_{2}$, also known as ceria, which has a fluorite structure with cerium ions in the $4+$ oxidation state. The $\mathrm{Ce}_{2} \mathrm{O}_{3}$ phase, with an orthorhombic structure (Atype phase), is relatively less stable at ambient conditions. Several additional metastable phases with different stoichiometry can be stabilized in specific conditions [9], among them the $\mathrm{Ce}_{2} \mathrm{O}_{3}$ bixbyite (c-type) phase deserves a particular relevance, since it can be obtained from the most stable fluorite-type $\mathrm{CeO}_{2}$ phase by removing $25 \%$ of the oxygen lattice atoms in an ordered way and allowing for a slight structural rearrangement [10].

The (111) surface of the $\mathrm{CeO}_{2}$ phase is the thermodynamically most stable one, followed by the (100) and (110) surfaces, the latter two being polar [11]. The repeating unit along the (111) direction is an O-Ce-O triple layer, which in the following will be referred to as a monolayer (ML). Cerium oxide ultrathin films exposing the (111) surface can be obtained by epitaxial growth on metallic single crystal substrates with six-fold surface symmetry such as (111) surfaces of cubic structures [12-18], or hcp (0001) surfaces [14,19,20]. The lattice mismatch between cerium oxide 
and most of the metal substrates is quite large and it amounts to approximately $30-40 \%$. Nevertheless, films with a (111) surface orientation and a very good epitaxial quality have been obtained [15,17,21,22]. The (100) and (110) surface orientation can be stabilized through epitaxy using substrates with a very small lattice mismatch with $\mathrm{CeO}_{2}$. These are typically non-metallic and include $\mathrm{Si}$ [22,23], YSZ [24] and $\mathrm{SrTiO}_{3}[25,26]$. However, most of the studies performed using non metallic substrates focus on thick films with several tens of nm thickness, possibly because of the difficulties in applying surface science techniques, necessary to obtain information at the ultrathin limit, on substrates with low conductivity.

The first and main part of this section will be dedicated to studies of cerium oxide (111) ultrathin films, and the final part to the investigations concerning ultrathin films exposing less stable surfaces. Important aspects connected to reducibility at the two- dimensional limit will be reviewed and discussed, with focus on: i) structure, morphology and defectivity, ii) charge transfer and intermixing at the interface, iii) modifications in structure and morphology induced by reduction, iv) stabilization of metastable structures induced by dimensionality and/or epitaxial constraints.

Pioneering works studying ultrathin cerium oxide films on the Pt(111) surface date back to the midnineties and they were motivated by the idea that a deep understanding of ceria-based materials obtained from studies of single crystalline surfaces and films of different thickness, structure and morphology could help improving the activity of cerium oxide supports in three way catalytic converters $[12,13,27,28]$. Cerium oxide films were grown either by deposition of metallic cerium followed by post-oxidation [12,27] or by oxidation of Ce-Pt surface alloys [13,28]. Already these early works pointed out that ultrathin films in the ML and sub-ML range contain a non negligible $\mathrm{Ce}^{3+}$ concentration, while thicker films can be fully oxidized $[12,13]$. As will be clearer in the following, this aspect is rather crucial in trying to identify a charge transfer from the metal substrate and/or a dimensionality-induced decrease of oxygen vacancy formation energy induced by the lower average $\mathrm{O}$ coordination of $\mathrm{Ce}$ ions at the early stages of the growth. The structure of the films was found to be disordered unless thermal treatments at temperatures higher than $700 \mathrm{~K}$, which stabilize the fluorite (111) phase, are performed [12,13]. Thermally-induced instabilities were observed above $1000 \mathrm{~K}[12,13]$. Interestingly, films which fully cover the substrate showed a significant activity towards $\mathrm{CO}$ oxidation, higher than the one of the bare $\operatorname{Pt}(111)$ surface [12]. An important role of the metal-oxide interfacial sites and of non-(111) oriented surfaces was also hypothesized, based on the high activity of films which do not fully cover the substrate [12].

The results of the early studies provided a strong motivation for subsequent works, using more controlled growth procedures, combined with a variety of techniques for surface characterization down to the atomic level. Cerium oxide ultrathin films with the (111) fluorite structure were grown on $\operatorname{Pt}(111)$ [17,21,28,29], $\mathrm{Rh}(111)$ [15,16], $\mathrm{Ru}(0001)$ [14,20], Ni(111) [14], $\mathrm{Cu}(111)$ [30,31], $\mathrm{Au}(111)$ [32], $\operatorname{Pd}(111)$ [33] and $\operatorname{Re}(0001)$ [34] substrates. On one side these studies confirmed the enhanced reactivity of bidimensional cerium oxide films compared to the clean substrates and the importance of metal-oxide interface sites [31,35], on the other they clarified important fundamental aspects linked to the reducibility of low-dimensional supported cerium oxide systems $[15,29,30]$.

In general, the studies of ultrathin supported cerium oxide films and islands were motivated by the need to identify the active sites in real catalysts made of metallic nanoparticles supported on cerium oxide. Several works specifically addressed the reactivity of metal-supported cerium oxide systems 
and towards selected reactions [31,35,36,37]. A catalytically active role of the interface between cerium oxide and $\mathrm{Rh}(111)$ in $\mathrm{CO}$ oxidation was suggested for example by Eck et al., who identified preferential $\mathrm{CO}$ adsorption sites near the phase boundaries of the oxide islands [36]. Suchorski et al. showed that the catalytic activity towards $\mathrm{CO}$ oxidation of cerium oxide nanoislands on $\mathrm{Pt}(111)$ is remarkably increased compared to the bare Pt(111) surface [35]. By comparing systems with different density of step edges they suggested the observed increase to be due to the different electronic properties at the islands perimeter [35]. A similar role for the oxide metal interface, combined with the low dimensionality of cerium oxide, was identified for the $\mathrm{CO}$ oxidation reaction and for the water gas shift reaction on the cerium oxide $/ \mathrm{Cu}(111)$ inverse catalyst model system $[31,37]$. Studies of this kind stimulated more accurate work on cerium oxide bidimensional structures and systematic investigation of the influence of the preparation conditions and of the substrate used on the structure, morphology, defectivity and reducibility of the investigated systems.

On most substrates post-growth thermal treatments in $\mathrm{O}_{2}$ have been found to improve the surface morphology, stoichiometry and structure of the cerium oxide terraces obtained $[17,20]$. The ultrathin films have relatively large coincidence cells with the underlying metal surface giving origin to moiré patterns in scanning tunneling microscopy (STM) images [20,38] or in low energy electron diffraction (LEED) patterns [15]. The coincidence cells with the lowest strain typically involve $5 \times 5$ ceria surface cells and $7 \times 7$ substrate surface cells (hereafter termed 5:7 coincidence), however at the ultrathin limit smaller coincidence cells, implying a larger strain, can be stabilized. This phenomenon has been observed for example on the $\operatorname{Pt}(111)$ substrate, where ultrathin films have a compressed surface structure and an interatomic distance comparable with the 3:4 coincidence cell, while thicker films have the relaxed bulk structure [17,21,39]. At the ultrathin limit a contraction of the in plane lattice parameter has been observed also using $\mathrm{Rh}(111)$ as a substrate [15], and even on $\mathrm{Cu}(111)$ substrates [38]. The evidence for a lattice contraction also on $\mathrm{Cu}(111)$, on which cerium oxide could adopt a 3:2 coincidence with the substrate with negligible strain, demonstrates that the tendency for lattice contraction is probably an intrinsic property linked to reduced dimensionality [38].

The deposition of cerium oxide amounts in the ML range typically results in the formation of large flat islands of ML or multi-layer height [15,17,20]. Procedures to obtain continuous films of monolayer thickness with almost complete coverage have been identified on the $\mathrm{Cu}(111)$ substrate, using low temperature $(110 \mathrm{~K})$ growth in $\mathrm{O}_{2}$ followed by post-annealing in $\mathrm{O}_{2}$ at $770 \mathrm{~K}$ [18]. Ultrathin cerium oxide films grown in strongly oxidizing conditions contain a non-negligible concentration of $\mathrm{Ce}^{3+}$ ions on the $\mathrm{Pd}(111)$ [33], $\mathrm{Pt}(111)$ [17] and on the $\mathrm{Rh}(111)$ substrate [15]. In the latter case a preferential localization of the $\mathrm{Ce}^{3+}$ sites at the interface was deduced by comparison of x-ray photoemission spectroscopy (XPS) and resonant valence band photoemission spectra. Valence band resonant photoemission, having a smaller probing depth than XPS, does not show any significant $\mathrm{Ce}^{3+}$ concentration on the surface. The non-negligible $\mathrm{Ce}^{3+}$ concentration detected by XPS is therefore ascribed to interface sites [15]. This represents a strong evidence of possible charge transfer from the metallic substrate towards the cerium oxide films. Effects such as charge transfer can indeed significantly alter the properties of two-dimensional cerium oxide films, and a definite assignment of the origin of reduced interfacial states requires a theoretical description of the system. On the $\mathrm{Cu}(111)$ substrate density functional theory (DFT) calculations showed that a very relevant charge transfer from the metal to the oxide takes place, yielding to the reduction of a 
full layer of interfacial Ce ions [40]. DFT calculations on a $1 \mathrm{ML}$ cerium oxide film supported on $\mathrm{Pt}(111)$, instead, evidenced electrostatic interactions between the topmost Pt layer and the interfacial oxygen atoms in the oxide, which cause a significant corrugation of both the film surface and of the interfacial Pt layer [41]. The charge transfer between Pt and Ce ions is significant only in the interfacial sites where the distance between the two atoms is short [41].

Not only the size, but also the shape and defects of the terraces obtained on the surface of ultrathin cerium oxide films seem to depend on the preparation conditions. On $\mathrm{Ru}(0001)$, using high temperature $(\mathrm{T}>800 \mathrm{~K})$ growth and post-growth annealing $(\mathrm{T} \sim 1000 \mathrm{~K})$ in oxygen atmosphere $\left(\mathrm{P}>10^{-7}\right.$ mbar), ultrathin films with point defects, linear defects ascribed to grain boundaries and round terrace step edges have been obtained [20]. The presence of grain boundaries, possibly induced by three-dimensional growth mode at the early stages of film formation [20], is not suppressed by room temperature growth followed by annealing of ceria films using a $\operatorname{Pt}(111)$ substrate [17]. On this substrate ultrathin films present terraces with straight edges, oriented along the substrate main symmetry directions [17]. Thicker films instead show more rounded terrace edges [17]. This is possibly caused by the stabilization of less stable step edges by the proximity of the metallic substrate in ultrathin films. A detailed characterization of the film step edges for various preparation conditions showed that depending on the heating temperature different step types can be obtained. The different steps are rationalized in terms of stability of the exposed facets and analyzed in terms of electronic properties [42]. One-dimensional electronic states have been found to develop on specific step types, and at domain boundaries as shown in figure 1, which reports STM images acquired at different sample biases.

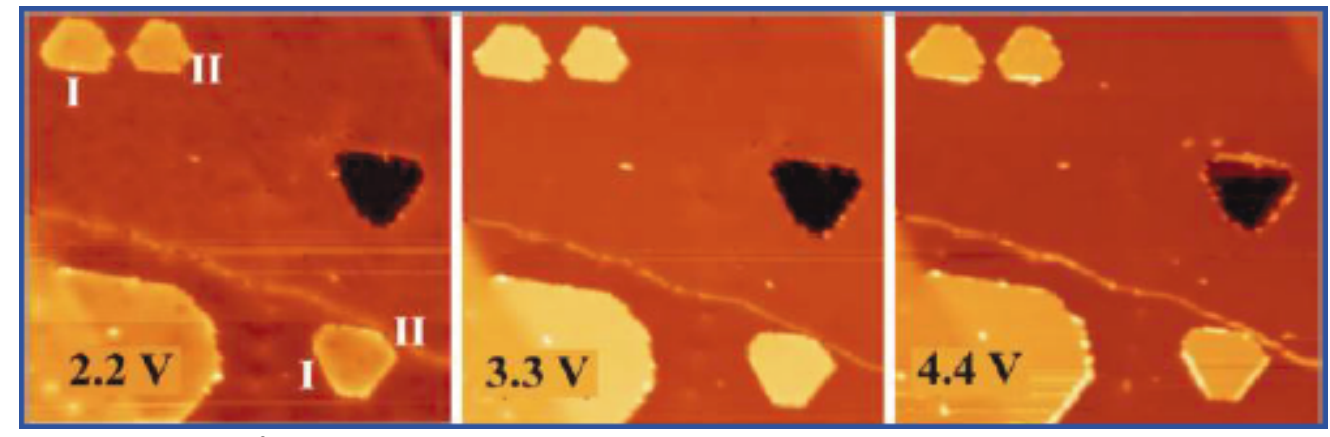

Fig.1: $65 \times 65 \mathrm{~nm}^{2}$ STM topographic images of a $6 \mathrm{ML}$ cerium oxide film grown on $\mathrm{Ru}(0001)$ with islands and holes exposing different step edge orientation. Steps indicated as I and domain boundaries show an increased apparent height at $4.4 \mathrm{~V}$ sample bias, while steps indicated as II do not change apparent contrast with bias. Reprinted with permission from Nilius et al. [42] Copyright 2012 American Chemical Society.

The step edges exposed by cerium oxide two-dimensional films show similarities to those exposed by bulk ceria surfaces, although in this case depressions rather protrusions are most frequently observed on the surface [43]. A non-negligible density of point defects has been often observed on ultrathin film terraces [21]. The defects are very similar to the ones formed on bulk surfaces, the most common being surface oxygen vacancies, also imaged as trimers and as linear arrays, and subsurface oxygen vacancies [21]. Defects can also be intentionally induced by electron bombardment of the film surface [44]. A work by Jerratsch et al. identified some degree of delocalization of the charge left after $\mathrm{O}$ vacancy formation [44]. The delocalization of charge after O release has been highly debated also on bulk surfaces $[45,46]$, and at reduced dimensionality some non negligible degree of delocalization has been clearly identified [5,47]. 
Cerium oxide films can be reduced by different procedures, including thermal annealing in vacuum $[15,17,29,35]$, growth of metallic Ce in low oxygen background pressure [14,16,48], ion bombardment [49] or exposure to reducing gases [49-51]. Vacuum thermal treatments often induce also a structural and morphological modification, pointed out to be strongly dependent on the initial film thickness [15,29]. In particular, the temperature at which reduction starts is lower for thinner films, which also show an apparently higher final degree of reduction [15,29]. Indeed it is difficult to determine the absolute amount of $\mathrm{Ce}^{3+}$ ions formed in the different samples by the different treatments, given the unknown shape of the depth profile of $\mathrm{O}$ vacancy concentration, and the different depth sensitivity of the techniques used to measure the $\mathrm{Ce}^{3+} / \mathrm{Ce}^{4+}$ ratio. However, the idea of having a higher density of $\mathrm{Ce}^{3+}$ sites in the surface layer after reduction is generally accepted [29]. A dependence of the onset of cerium oxide surface reduction on the growth temperature of the film, and hence on the density of reduced coordination sites, has been pointed for films grown on the $\mathrm{Cu}(111)$ substrate [38]. A very interesting effect, shown to take place on the surface of a thin ceria film on $\mathrm{Rh}(111)$ after reduction, is the formation of an ordered array of surface defects, clearly visible in the STM images (figure 2), and ascribed to triple oxygen vacancies [52]. The smaller energy for the formation of vacancies at specific sites of the 5:7 coincidence lattice is ascribed to the local surface stress [52].
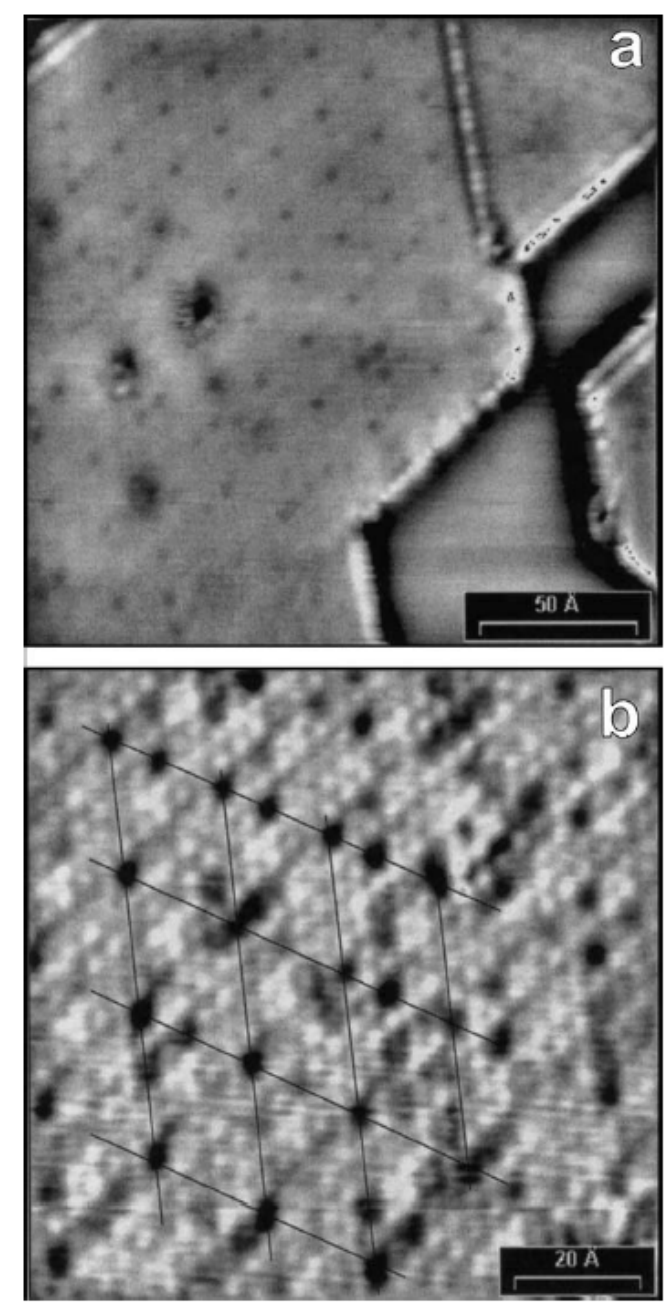

Fig.2: STM images of a $0.5 \mathrm{ML} \mathrm{CeO}_{2-\mathrm{x}}$ film grown on the Rh(111) surface after annealing at $\sim 900 \mathrm{~K}$. (a) $200 \times 200 \AA^{2}$; $0.93 \mathrm{~V} ; 0.86 \mathrm{nA}$. (b) $100 \times 100 \AA^{2} ; 0.80 \mathrm{~V} ; 1.05 \mathrm{nA}$. The grid of black lines evidences the superlattice of defects, 
ascribed to triple oxygen vacancies. Reprinted with permission from Casterllarin-Cudia et al. [52] Copyright 2004 Elsevier.

The surface of reduced ceria films on $\operatorname{Pt}(111)$ instead shows a corrugated morphology with biasdependent features tentatively ascribed to electronic modifications induced by reduction [29]. Interestingly, ultrathin reduced cerium oxide phases show peculiar surface reconstructions (figure 3 ), whose origin is still under investigation and appears to be linked to the presence of the underlying substrate [29]. The effect of the heating time and heating rate on the final degree of reduction of the films has been also pointed out to be very important [29]. Some extra-periodicities have been observed also on the $\mathrm{Cu}(111)$ substrate after deposition of variable amounts of metallic cerium on a $\mathrm{CeO}_{2}$ buffer layer, followed by annealing in UHV [53]. Some of them are commonly observed also on the surface of thick films after reduction [54] and correspond to metastable bulk phases such as the $\mathrm{Ce}_{7} \mathrm{O}_{12}$ phase and the c-type bixbyite phase.
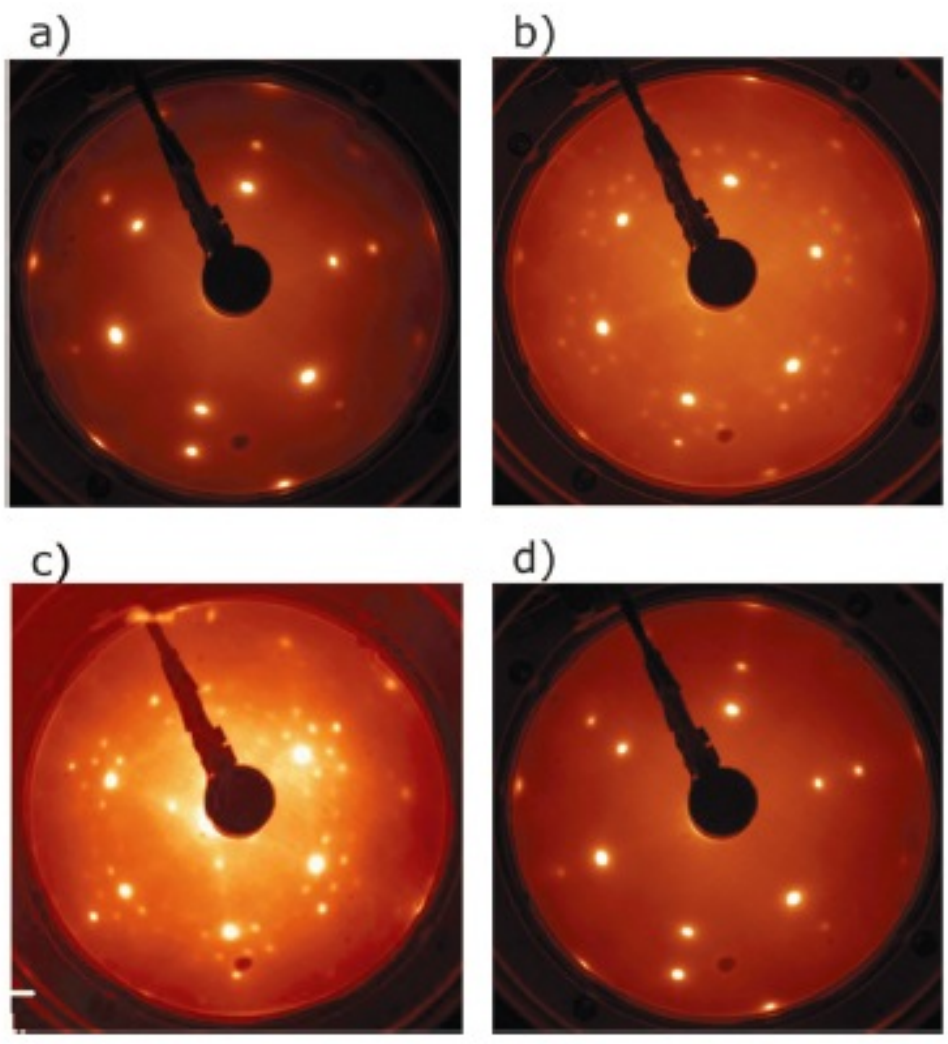

Fig.3 LEED patterns $(\mathrm{Ep}=80 \mathrm{eV})$ of a $2 \mathrm{ML}$ cerium oxide film (a) as prepared, (b) after intermediate reduction by heating in UHV at $770 \mathrm{~K}$ for $30 \mathrm{~min}\left(\mathrm{c}_{\mathrm{Ce} 3+} \sim 40 \%\right.$, as measured by XPS), showing the $(3 \times 3)$ and the $9 / 4(\sqrt{3} \times \sqrt{ } 3) \mathrm{R} 30^{\circ}$ phase (c) after strong reduction by heating in UHV at $1040 \mathrm{~K}$ for $15 \mathrm{~min}\left(\mathrm{c}_{\mathrm{Ce} 3+} \sim 60-80 \%\right)$ showing the $9 / 4(\sqrt{3} \times$ $\sqrt{3}) \mathrm{R} 30^{\circ}$ phase (d) after re-oxidation by heating in $\mathrm{O}_{2}$ at $1040 \mathrm{~K}$. Luches et al. [29] - Reproduced by permission of the PCCP Owner Societies.

The full reversibility of the reduction process was demonstrated for ceria films of different thickness on Pt(111) [29]. We note here that this aspect is not trivial, and it is linked to the reducibility of the films. Cerium oxide films on a $\mathrm{Si}(111)$ substrate reduced by vacuum thermal treatments under conditions similar to those used in ref. 29, showed a non reversible reduction of $\mathrm{Ce}$ ions from the $4+$ state to the $3+$ state [23]. This process was ascribed to the formation of interface cerium silicate phases which are not reducible [23]. Interfacial atom exchange during growth was also observed using $\mathrm{Ni}(111)$ and $\mathrm{Cu}(111)$ substrates, and they were shown to have a non-negligible 
influence on the stoichiometry of the films at the ultrathin limit [14,31]. On the $\mathrm{Au}(111)$ substrate the formation of $\mathrm{Au} / \mathrm{Ce}$ alloys hinders the good ordering of extended two-dimensional films [32].

Substoichiometric films were also obtained by evaporation of $\mathrm{Ce}$ on $\mathrm{Ru}(0001)$ and on $\mathrm{Ni}(111)$ in low oxygen pressure $\left(\mathrm{P}_{\mathrm{O}_{2}} \sim 10^{-8} \mathrm{mbar}\right)$ and they were found to have the fluorite structure with a high concentration of oxygen vacancies in at least the topmost oxygen atom layers compatible with a bixbyite structure rather than to a hexagonal $\mathrm{Ce}_{2} \mathrm{O}_{3}$ structure [14].

As reported above, several works have shown some degree of reducibility of cerium oxide ultrathin films, which is typically higher than the bulk, but they also evidenced that fully reduced states are very difficult to be achieved $[15,29]$. This may be linked to the fact that it is easy to form oxygen vacancies in the fluorite structure up to a certain density, or to the fast (partial) reversibility of the reduction process when high $\mathrm{Ce}^{3+}$ concentrations are obtained. The cubic c-type bixbyite phase, with $25 \%$ oxygen vacancies is in fact unstable in the bulk form and a full cerium oxide reduction may require a transition to the most stable hexagonal A-type phase. A metastable epitaxial cubic ctype $\mathrm{Ce}_{2} \mathrm{O}_{3}$ phase has been stabilized on the $\mathrm{Cu}(111)$ surface by deposition of metallic $\mathrm{Ce}$ on a $\mathrm{CeO}_{2}$ buffer layer followed by $900 \mathrm{~K}$ annealing [55]. The film shows a well ordered surface with a (4x4) reconstruction with respect to the $\mathrm{CeO}_{2}(111)$ surface (figure 4). The reconstruction is ascribed to ordered arrays of quadruple oxygen vacancy clusters and corresponds to the bulk termination of $\mathrm{c}-\mathrm{Ce}_{2} \mathrm{O}_{3}$ [55]. Although the film thickness is as high as a few nm, the influence of the substrate is considered to be determinant for the stabilization of the observed phase, ascribed to the effect of the tetragonal strain induced by the $\mathrm{Cu}$ substrate [55]. A phase with a similar c-type bixbyite structure in the form of an ultrathin film was also stabilized on a Cl-passivated $\mathrm{Si}(111)$ surface [22]. 

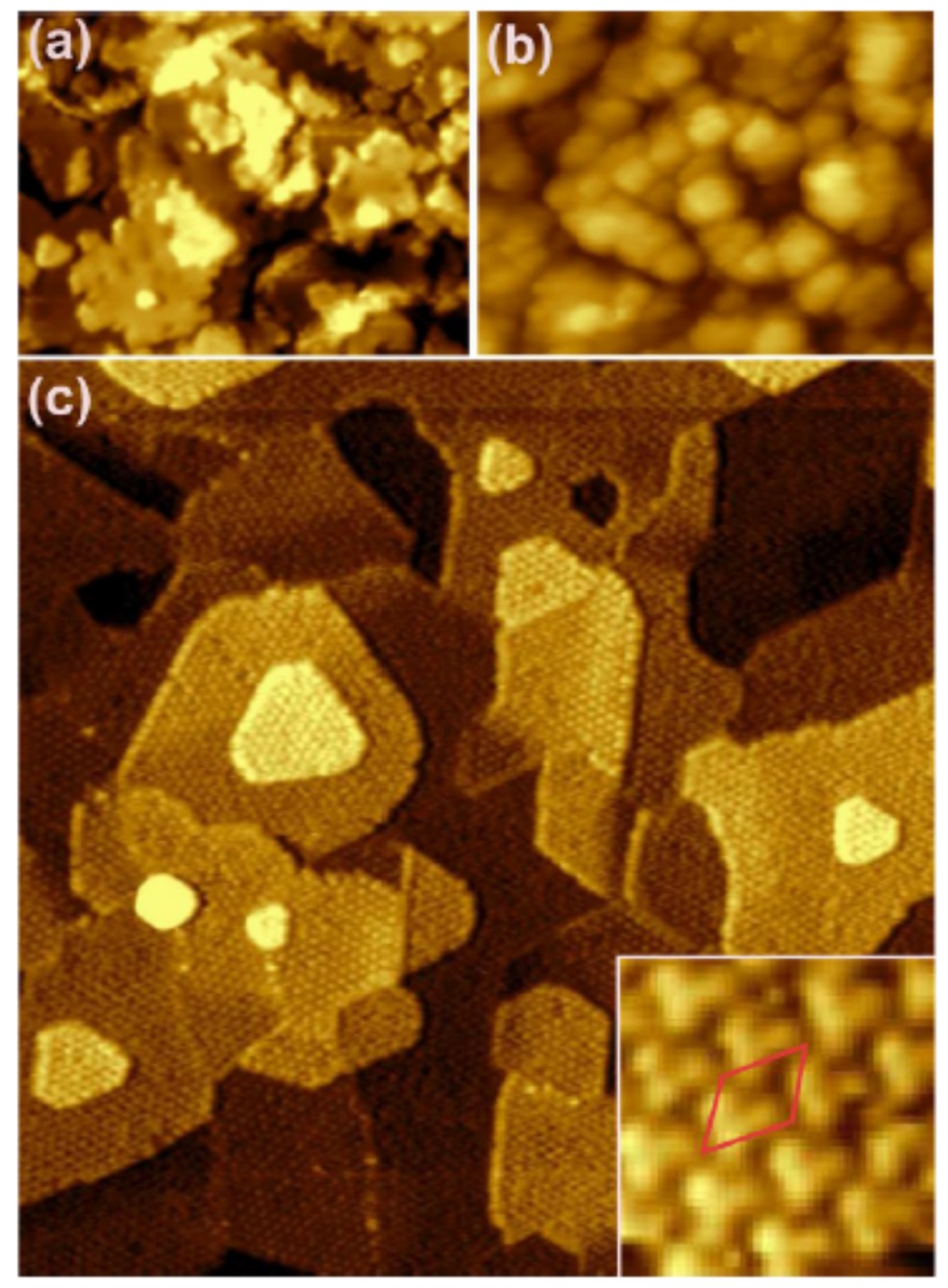

Fig.4: STM images showing the different stages of formation of c- $\mathrm{Ce}_{2} \mathrm{O}_{3}$ films on $\mathrm{Cu}(111)$. (a) $\mathrm{CeO}_{2}$ buffer, (b) $\mathrm{CeO} 2$ buffer with subsequent metallic Ce deposition, (c) ordered c- $\mathrm{Ce}_{2} \mathrm{O}_{3}$ layer obtained by annealing (b) in vacuum at $900 \mathrm{~K}$. Inset: high-resolution image and surface unit cell (red rhombus) of the $\mathrm{c}-\mathrm{Ce}_{2} \mathrm{O}_{3}$ layer. Images a-c are to scale. Image width (a,b) $60 \mathrm{~nm}$, (c) $120 \mathrm{~nm}$, (inset) $6 \times 6 \mathrm{~nm}^{2}$. Reprinted with permission from Stetsovych et al. [55] Copyright 2013, American Chemical Society.

The exposed works show that ultrathin cerium oxide films offer new opportunities in view of obtaining modifications of the material properties, and in particular for the stabilization of metastable structural phases. This last issue has been investigated also in a rather recent theoretical investigation aimed at identifying the most stable $\mathrm{Ce}_{2} \mathrm{O}_{3}$ structures at the ultrathin limit [56]. The work, using simulated mechanical annealing searches and DFT calculations, shows that different ultrathin film structures are stable at different values of the in plane lattice parameter and it identifies in particular a new structure, which does not correspond to any known bulk crystalline polymorph, which is more stable than the A-type and than the c-type $\mathrm{Ce}_{2} \mathrm{O}_{3}$ structures at specific, relatively large, in-plane lattice parameters (figure 5) [56]. 


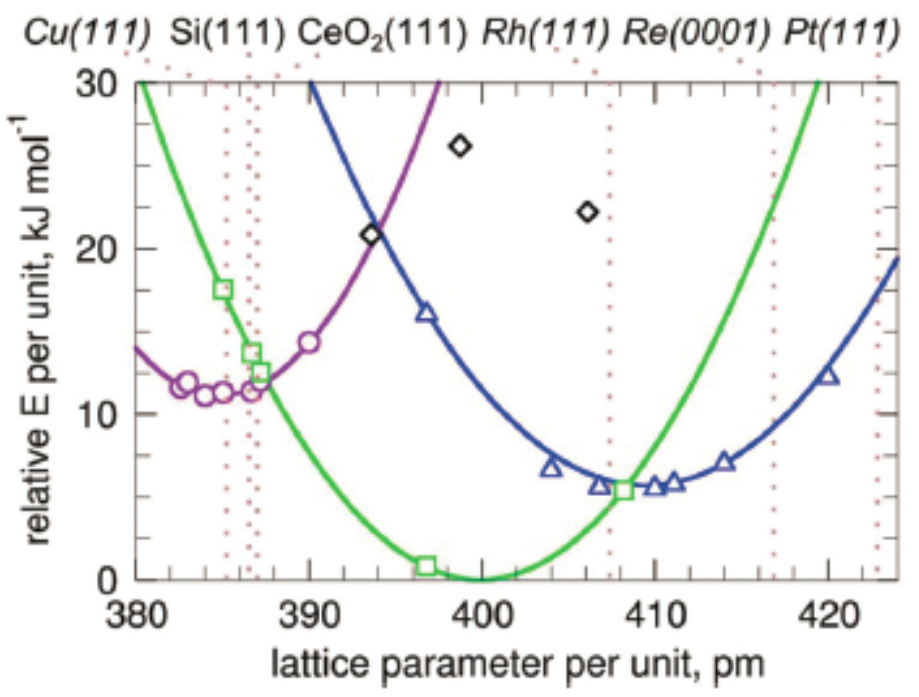

Fig.5: Results of DFT calculations for $4 \mathrm{ML} \mathrm{Ce}_{2} \mathrm{O}_{3}$ films with different structure: A-type (circles), bixbyite (squares) NF1 (triangles), NF2-4 (diamonds). Energies (relative to that of the optimized bixbyite film) and lattice parameters are given per $\mathrm{Ce}_{2} \mathrm{O}_{3}$ unit. Vertical dotted lines indicate lattice parameters of possible supports for film growth (multiplied by $3 / 2$ for transition metals - highlighted by italics). Kozlov et al. [56] - Published by The Royal Society of Chemistry.

As mentioned at the beginning of this section, a few studies have also been focused on the stabilization of ultrathin cerium oxide films exposing surfaces different from the (111) on metal substrates. For example, the stabilization of cerium oxide nanoislands exposing (100) facets, with thickness down to $1 \mathrm{ML}$, has been shown to be possible using a $\mathrm{Cu}(111)$ surface and highly oxidizing growth conditions [57]. The stabilization mechanism invoked is the formation of a copper oxide with a rectangular unit cell at the interface, which imposes an epitaxial constraint and shares an $\mathrm{O}$ layer with cerium oxide to compensate polarity (figure 6) [57]. On the same substrate the presence of an interfacial $\mathrm{CeO}_{2}(100)$ layer supporting three dimensional $\mathrm{CeO}_{2}$ nanoislands with (100) surface orientation has also been observed to coexist with the (111) $\mathrm{CeO}_{2}$ orientation [58]. 


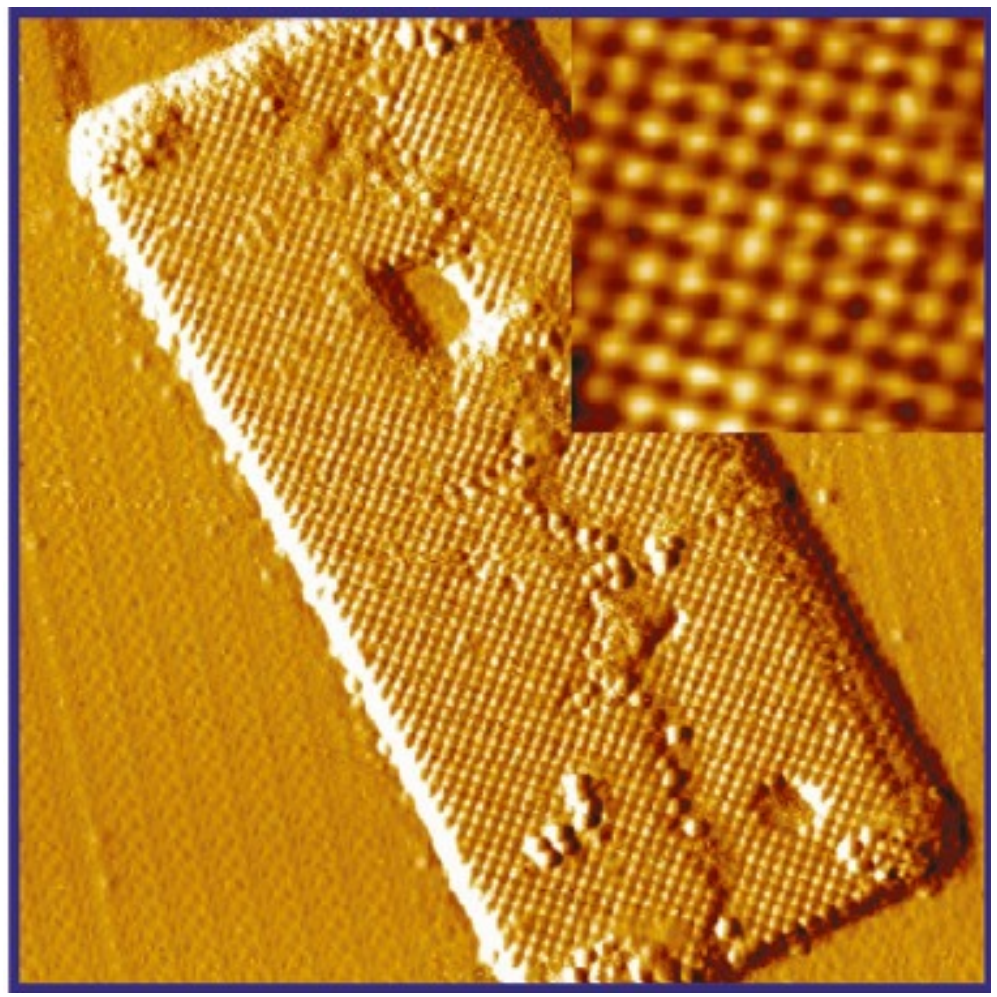

Fig. 6: High resolution STM images of $\mathrm{CeO}_{2}(100)$ phases prepared by Ce deposition in $5 \times 10^{-7}$ mbar of $\mathrm{O}_{2}$ at $650 \mathrm{~K}$ on a copper oxide surface, formed by oxidizing $\mathrm{Cu}(111)$ with $\mathrm{NO}_{2}$ at $600 \mathrm{~K}$. The large-scale images with size $40 \times 40 \mathrm{~nm}^{2}$ is shown in the derivative mode. Reprinted with permission from Yang et al. [57] Copyright 2011 American Chemical Society.

A recent study pointed out the formation of ceria nanocrystallites exposing (100) facets after thermal treatments in vacuum of continuous (111) cerium oxide films grown on $\mathrm{Ru}(0001)$ [59]. The nanostructures, of nanometric height and several tens of nm lateral size, compensate their polarity through surface reconstructions similar to those hypothesized for the bulk (100) orientation [11]. Open aspects which may contribute to a better understanding of less stable surfaces, also in view of preparing two-dimensional films with less stable orientation, are the understanding of the mechanisms which preferentially stabilize this phase under highly reducing conditions compared to other phases, and the possible reasons for the existence of the (001) orientation only at relatively large heights of a few nm. Although studies of cerium oxide films exposing less stable surfaces at the two-dimensional limit are in general rather scarce, they have a great potential interest in view of the expected smaller surface oxygen vacancy formation energy, due to the lower coordination of surface $\mathrm{O}$ atoms. Furthermore, the possible formation of new structural phases driven by the compensation of polarity at reduced dimensionality may also open up new perspectives, in analogy with the case of non-reducible oxides [60].

\section{Titanium oxide two-dimensional films}

Titanium oxide is another case study for reducible oxides. Unlike cerium ions which are stable only in the $3+$ and $4+$ oxidation states, titanium ions can have different oxidation states, the most common ones being $\mathrm{Ti}^{2+}, \mathrm{Ti}^{3+}, \mathrm{Ti}^{4}$, giving rise to various oxides. The most stable oxide is $\mathrm{TiO}_{2}$, 
also known as titania, which can present different structural phases, the most important ones being rutile, anatase and brookite.

Ultrathin titanium oxide films grown on metal substrates have been the subject of extensive research over the last twenty years, as they can give rise to novel nanostructures and to a rich variety of phases which have been studied using surface science techniques. Stoichiometric and non-stoichiometric phases with different atomic structures can be obtained through the growth on single crystal metal surfaces, using simple experimental procedures: deposition of Ti in a vacuum chamber in controlled pressure of residual oxygen, i.e. reactive deposition, post-oxidation of $\mathrm{Ti}$ metal films, reduction in vacuum by heating the films in UHV or in controlled residual hydrogen pressure. A selection of results reported in the literature, with focus on peculiar properties arising at two-dimensions and in particular on reducibility-related issues, are hereby reported and discussed.

Experiments on titanium oxide ultrathin films grown on $\mathrm{Cu}(100)$ were carried out by different groups [61-63]. Maeda et al. [61] deposited metallic $\mathrm{Ti}$ on the $\mathrm{Cu}$ surface previously exposed to $\mathrm{O}_{2}$ $\left(\mathrm{P}=1 \times 10^{-6}\right.$ mbar at $\left.\mathrm{T}=330 \mathrm{~K}\right)$, and oxidized the resulting film by post-growth $\mathrm{O}_{2}$ dosage $(\mathrm{P}=1 \times$ $10^{-7}$ mbar at $\mathrm{T}=623 \mathrm{~K}$ ). A two-dimensional growth of an $\mathrm{O}^{2-} / \mathrm{Ti}^{4+} / \mathrm{O}^{2-}$ trilayer with $\mathrm{TiO}_{2}$ stoichiometry was deduced from XPS data. LEED patterns showed a hexagonal geometry with two domains rotated by $90^{\circ}$ with respect to each other, and an in-plane lattice constant of $0.29 \mathrm{~nm}$. The study also indicates that this phase is unstable for coverages beyond a single $\mathrm{O}^{2-} / \mathrm{Ti}^{4+} / \mathrm{O}^{2-}$ trilayer. The model proposed by Maeda et al. [61] for the atomic geometry of the trilayer is analogous to the one deduced for the quasi-hexagonal structure formed by titanium oxide on the oxidized (110) surface of the NiTi alloy [64]. A quasi-hexagonal phase was also observed for titanium oxide films obtained by reactive deposition of $\mathrm{Ti}\left(\mathrm{P}=1 \times 10^{-6} \mathrm{mbar}, \mathrm{T}=573 \mathrm{~K}\right)$ on $\mathrm{Cu}(100)$ previously saturated with chemisorbed oxygen $[63,65]$. The chemisorption resulted in a $(\sqrt{ } 2 \times 2 \sqrt{ } 2) R 45^{\circ}$ LEED pattern with $\mathrm{Cu}$ missing-row reconstruction. At low Ti coverage $\left(\theta_{\mathrm{Ti}}<0.5 \mathrm{ML}\right)$ the same group observed a LEED pattern with a centred rectangular unit cell indicated as $\mathrm{c}-(\sqrt{2} \times \sqrt{2}) R 45^{\circ}$. STM data showed that the rectangular phase is associated with flat islands of uniform thickness, embedded within the outermost layer of the substrate. The stabilization of this phase is probably favoured by the missingrow reconstruction of the $\mathrm{O}-\mathrm{Cu}(100)$ surface used as substrate $[63,65]$. The quasi-hexagonal phase is observed at $\theta_{\mathrm{Ti}}>0.5 \mathrm{ML}$ (figure 7), however when the whole substrate surface is covered by the film $\left(\theta_{\mathrm{Ti}}=2.0 \mathrm{ML}\right)$ a regular hexagonal pattern is visible in the LEED, very similar to the one observed by Maeda et al. [61] An in-deep X-ray photoelectron diffraction (XPD) and LEED intensity analysis of the quasi-hexagonal phase, compared with DFT calculations, confirmed the OTi-O trilayer model, allowing to identify also the specific registry of the titanium oxide film with respect to the $\mathrm{Cu}(100)$ surface (figure 7) [65]. Interestingly, DFT provided also information about the electronic properties of the film, showing that the $\mathrm{O} 2 p$ and $\mathrm{Cu} 4 s p$ states overlap and that the film does not show an insulating behaviour because of an upshift of the $\mathrm{O} 2 p$ bands and a downshift of the Ti $4 s$ states, compared to the case of the ideal unsupported films. 

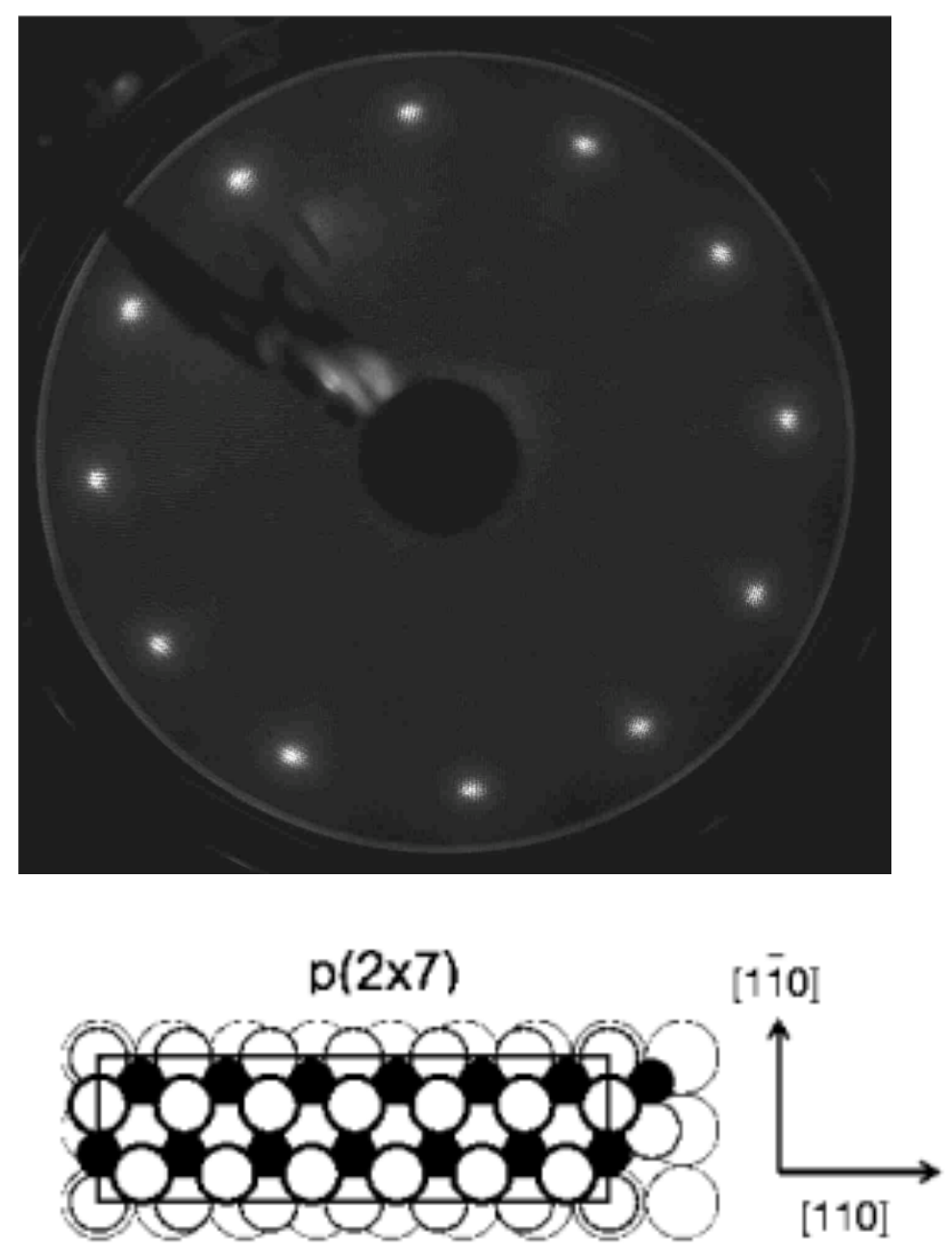

Fig. 7. a) LEED pattern observed a $\mathrm{TiO}_{2}$ film with the quasi-hexagonal structure on the $\mathrm{Cu}(001)$ surface. b) Atomistic model of the quasi-hexagonal phase of the O-Ti-O trilayer, with a rectangular $p(2 \times 7)$ unit cell, showing the registry of the film with the substrate. Reprinted with permission from Atrei et al. [65] Copyright 2009 American Chemical Society.

A $\mathrm{TiO}_{2}$ lepidocrocite-like structure was instead obtained at submonolayer coverage when the substrate used for the growth was Ag(100) [66]. Again, LEED, XPD and STM experiments results were compared with the results of DFT calculations. At coverages higher than $1 \mathrm{ML}$, islands with the rutile (110) surface begin to form [67]. Single domain titania nano-sheets with lepidocrocite structure were also observed when $\mathrm{TiO}_{2}$ films were grown on the $(1 \times 2) \operatorname{Pt}(110)$ surface [68].

Rutile $\mathrm{TiO}_{2}$ (110) films were also observed to grow on $\mathrm{W}(100)[69,70]$ and $\mathrm{O}(2 \times 1)-\mathrm{W}(100)[71]$ in two orthogonal domains along the $\mathrm{W}[010]$ and [001] directions. In the first case, the $\mathrm{TiO}_{2}$ films at coverage values between 5 and 30 ML reverted to the bulk structure, and a systematic splitting of the spots in the LEED pattern was attributed to the formation of a stepped surface, probably caused by a strain relaxation mechanism due to the compression of the long axis of the $\mathrm{TiO}_{2}$ unit cell. In the case of oxygen-reconstructed W(100) surface, STM images showed the formation of titanium oxide islands at low coverage following the orientation of the original missing rows induced by the $\mathrm{O}(2 \times 1)$ reconstruction (figure 8$)$. At increasing coverage, the islands extend and become higher, but $\mathrm{TiO}_{2}$ does not form a continuous film. The presence of point defects on the rutile islands, characteristic of the native rutile $\mathrm{TiO}_{2}(110)-(1 \times 1)$ surface was observed in high resolution STM 
images. $\mathrm{TiO}_{2}$ was also grown by reactive deposition and annealing on $\mathrm{Mo}(100)[72,73]$. At coverage values below $10 \mathrm{~nm}$, LEED showed a $(2 \sqrt{2} \times \sqrt{2}) R 45^{\circ}$ pattern, while STM images showed ordered atomic rows along the [010] and [001] substrate direction. Annealing procedures allowed reduction of the film, with the Ti ions oxidation state changing from $\mathrm{Ti}^{4+}$ only, to a mixture of $\mathrm{Ti}^{4+}$, $\mathrm{Ti}^{3+}$ and $\mathrm{Ti}^{2+}$ valence states, as evidenced by XPS. Similar studies were carried out also on $\mathrm{Mo}(110)$ [74,75], on which films of $\mathrm{TiO}_{2}$ with (100) orientation or $\mathrm{Ti}_{2} \mathrm{O}_{3}(0001)$ were obtained, depending on the preparation method. In particular the $\mathrm{Ti}_{2} \mathrm{O}_{3}(0001)$ phase was stabilized by initial deposition of a metallic Ti layer on the $\mathrm{Mo}(110)$ surface, followed by reactive Ti growth in $\mathrm{O}_{2}$ in the same conditions which lead to the formation of the $\mathrm{TiO}_{2}(100)$ phase [74]. STM images evidenced smooth surfaces with distinct flat terraces and well-defined step edges after annealing in $\mathrm{O}_{2}$ at $\mathrm{T}=900-1100 \mathrm{~K}$, while XPS data showed that the oxide films remained partially reduced after the treatment. In contrast, thin films annealed in oxygen at $\mathrm{T}=1200 \mathrm{~K}$ were fully oxidized but they exhibited a three-dimensional rough surface morphology [75].

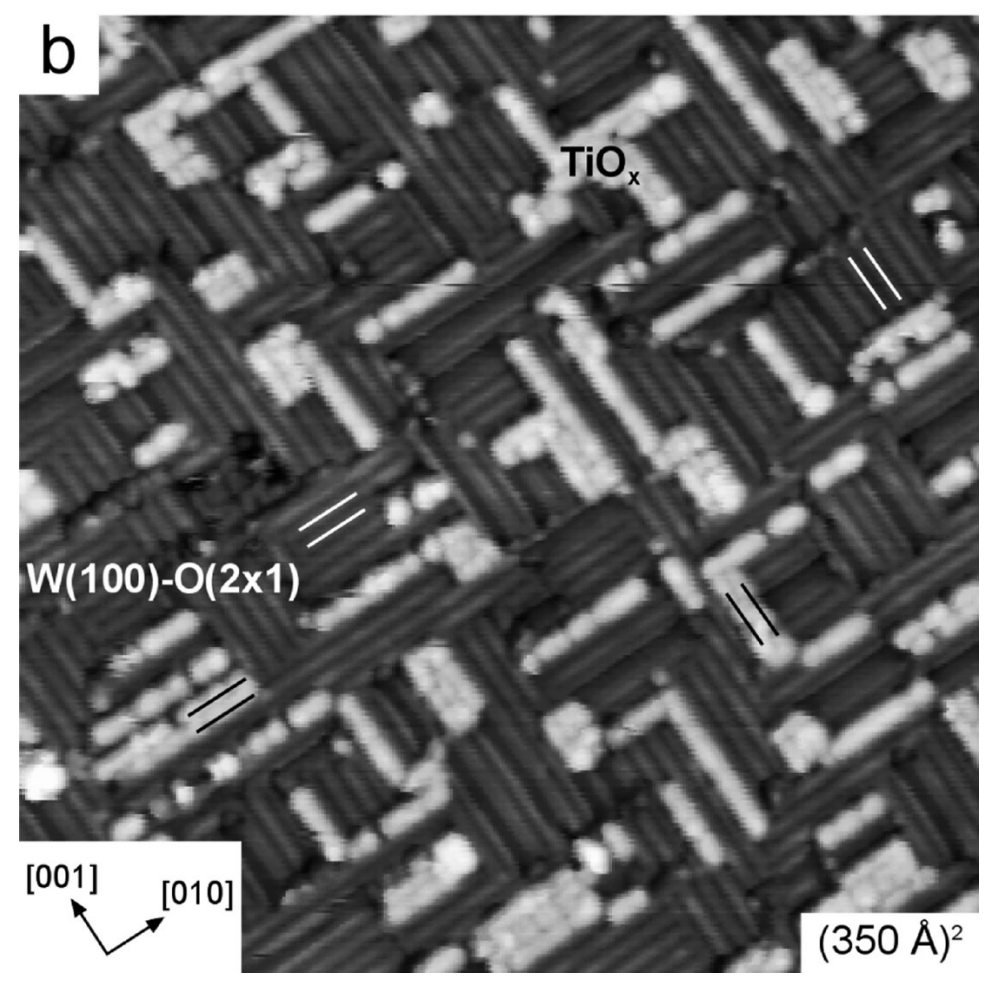

Fig. 8. STM image of a $0.2 \mathrm{ML}$ film of $\mathrm{TiO}_{\mathrm{x}}(110)$ on $\mathrm{W}(100)-\mathrm{O}(2 \times 1)$. An area of $\mathrm{TiO}_{\mathrm{x}}(110)$ and an area of the $\mathrm{W}(100)-$ $\mathrm{O}(2 \times 1)$ substrate are indicated. White lines are drawn over some of the $\mathrm{W}(100)-\mathrm{O}(2 \times 1)$ rows then duplicated, in black, over the TiOx rows to highlight the similar periodicity. The crystal directions correspond to those of the W(100) substrate. Reprinted with permission from Pang et al. [71] Copyright 2013 American Chemical Society.

The same group also reported formation of a well-ordered $(8 \times 2) \mathrm{TiO}_{\mathrm{x}}$ film on $\mathrm{Mo}(112)$, obtained by depositing $\mathrm{Ti}$ on $\mathrm{SiO}_{2}(\mathrm{ML}) / \mathrm{Mo}(112)$ followed by oxidation/annealing and a final anneal at $1400 \mathrm{~K}$ to completely remove residual $\mathrm{Si}$ [76]. This phase shows peculiar properties, including a strong interaction with $\mathrm{Au}$, which allowed a complete wetting of its surface, at variance with other oxide supports $[71,76]$. 


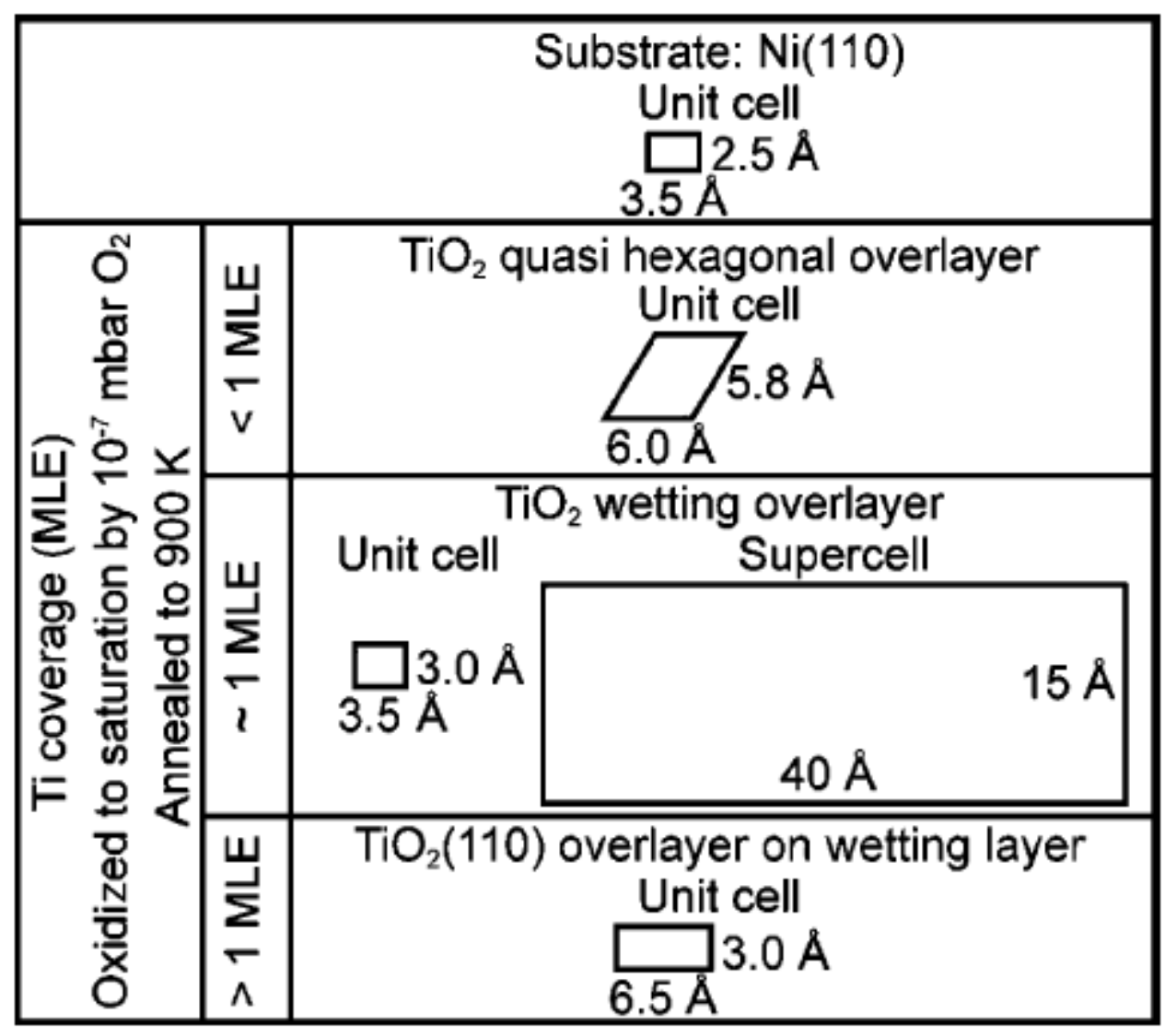

Fig. 9. Summary of the $\mathrm{TiO}_{2}$ phases grown on $\mathrm{Ni}(110)$. Reprinted with permission from Papageorgiou et al. [78] Copyright 2007 American Chemical Society.

Using a $\mathrm{Ni}(110)$ substrate for titanium oxide ultrathin films growth either a quasi-hexagonal phase or (110) rutile rods on a $\mathrm{TiO}_{2}$ wetting layer could be obtained, depending on the initial titanium coverage [78,79]. In both cases, XPS and x-ray absorption near edge spectroscopy (XANES) results demonstrated that $\mathrm{Ti}$ was fully oxidized. Figure 9 gives a summary of the $\mathrm{TiO}_{2}$ phases reported in ref. 76. The rutile and wetting layer phases showed a similar behaviour with respect to exposure to water at $\mathrm{P}=10^{-8}$ mbar, which resulted in coadsorption of both molecular water and hydroxyl groups. By dosing water at $\mathrm{P}=10^{-6}$ mbar hydroxylation of the thin films was observed. The process was found to be reversible by annealing at $\mathrm{T}=490 \mathrm{~K}$. STM images on rutile rods revealed a $(1 \times 2)$ reconstruction in some areas, ascribed to a reduced phase, very close to the one observed on the surface of bulk rutile $\mathrm{TiO}_{2}(110)$ single crystals [79]. The $(1 \times 2)$ islands disappear completely after

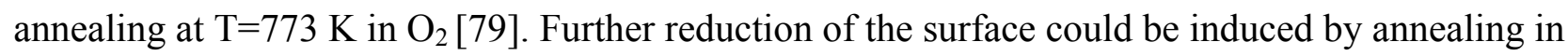
UHV at $\mathrm{T}=1110 \mathrm{~K}$, with observation of $\{132\}$ and $\{121\}$ families of crystallographic shear planes. In this respect the behaviour of ultrathin films is analogous to the one of the $\mathrm{TiO}_{2}(110)$ single crystal surface [80].

The study of titanium oxide films on Pt surfaces is particular relevant, in view of a deeper understanding of the phases formed in oxide-supported metal catalysts as a consequence of SMSI [8]. Experiments of Pt nanoparticles grown on $\mathrm{TiO}_{2}(110)$ surface revealed that the (111) oriented Pt islands were encapsulated within $\mathrm{TiO}_{2}$ regular films after annealing at $\mathrm{T}=1100 \mathrm{~K}$ with a subsequent change of the catalytic activity [81]. The encapsulation was observed and studied in detail also in 
the case of $\mathrm{Pd}$ on $(1 \times 2) \mathrm{TiO}_{2}(110)$ [82]. Some of the structures obtained in these systems were also observed on the reverse catalyst model $\mathrm{TiO}_{\mathrm{x}} / \mathrm{Pt}$ systems.

Matsumoto et al. used a number of experimental techniques for a complete study of titanium oxide grown on $\mathrm{Pt}(100)$ [77,83]. In particular, two different routes for film synthesis were used: in the first one a $\mathrm{Pt}_{3}$ Ti surface alloy was oxidized with $\mathrm{O}_{3}$ and annealed at $\mathrm{T}=1000 \mathrm{~K}$. The result was a smooth film composed of one layer of $\mathrm{Ti}_{2} \mathrm{O}_{3}$ with $(3 \times 5)$ superstructure, with flat terraces without islands, and with a structure similar to the $(1 \times 2)$ strands formed on the reduced $\mathrm{TiO}_{2}(110)$ surface. The second route was reactive deposition of $\mathrm{Ti}$ in $\mathrm{O}_{2}\left(\mathrm{p}=6.7 \times 10^{-7} \mathrm{mbar}\right)$ followed by annealing above $750 \mathrm{~K}$ in vacuum. In this case, a $(3 \times 5)$ structure could be observed for coverages lower than $1 \mathrm{ML}$, while a $(4 \times 3 \sqrt{5}) R 60^{\circ}$ structure was obtained after deposition of $2 \mathrm{ML}$. The proposed model for the observed reconstruction consists of $\mathrm{TiO}_{2}$ tetragonal nets with some $\mathrm{O}$ atoms in the second layer. The $(3 \times 5)$ structure was re-obtained after annealing above $950 \mathrm{~K}$ in vacuum. At increasing coverage and after annealing a $\mathrm{T}=1000 \mathrm{~K}, \mathrm{TiO}_{2}$ clusters were observed, coexisting with $\mathrm{Ti}_{2} \mathrm{O}_{3}(3 \times 5)$ and clean $\mathrm{Pt}(100)$ domains. Finally, after further annealing at $\mathrm{T}=1300 \mathrm{~K}$ the $\mathrm{TiO}_{2}$ clusters decomposed to form a $(2 \sqrt{2} \times 2 \sqrt{2}) R 45^{\circ}$ structure, proposed to be $\mathrm{Ti}_{5} \mathrm{O}_{8}$, and $(3 \times 5)$ domains.

Boffa et al. investigated titanium oxide films grown on $\mathrm{Pt}(111)$ for coverages ranging from 1 to 5 ML [84]. Two different structures were obtained depending on the sample pretreatment. In particular, annealing at temperatures between 770 and $970 \mathrm{~K}$ in $\mathrm{O}_{2}$ gave a $\left(\sqrt{ }(3 \times \sqrt{ } 43) R 7.6^{\circ}\right.$ three fold symmetric structure, with $\mathrm{TiO}_{2}$ stoichiometry and primitive cell $18.2 \AA \times 18.2 \AA$ size. Annealing in vacuum $(820-1120 \mathrm{~K})$ gave a second ordered overlayer with primitive cell of $18.2 \AA$ $\times 13.9 \AA$ size and $\mathrm{Ti}_{4} \mathrm{O}_{7}$ stoichiometry. Partial dissolution of Ti in Pt was observed after annealing at high temperatures, reducing the thickness of the films to approximately 1 ML [84].

A systematic work on titanium oxide films grown on $\operatorname{Pt}(111)$ was carried out during the last years [85-90]. The study first concentrated in ultrathin layers, with an amount of Ti lower than 1.2 MLE, where 1 MLE corresponds to the surface density of Pt atoms per unit area on the $\mathrm{Pt}(111)$ surface. By varying the Ti dose and the annealing conditions (temperature and oxygen pressure) six metastable phases with different long-range order were originally found [85]. The conditions leading to the different phases are summarized in figure 10. 


\section{a)}

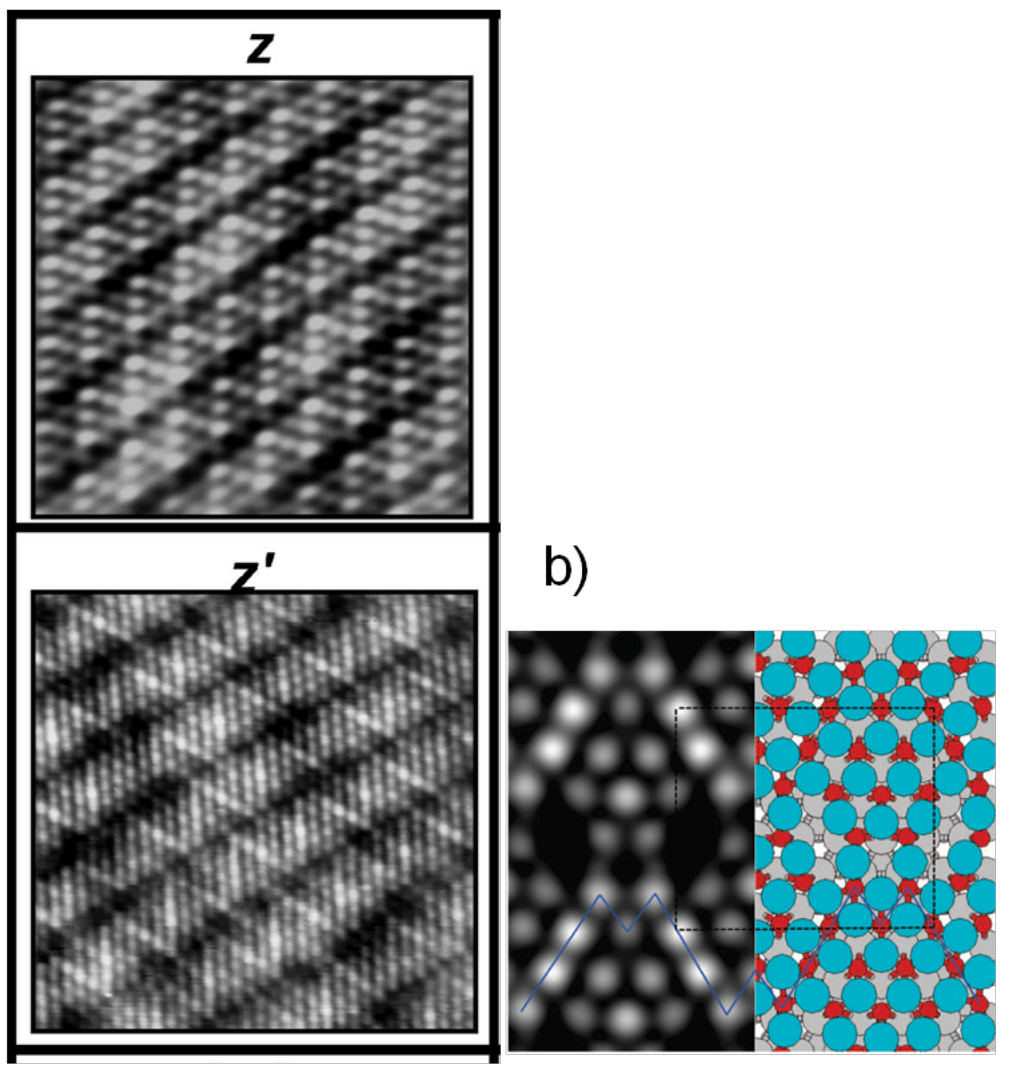

Fig. 11 a) atomically resolved image of the $z$ - and $z$ '-TiO phase on $\operatorname{Pt}(111)$. b) simulated STM image and structure of the $z$ ' phase, as obtained by DFT calculations. Reprinted with permission from Barcaro et al. [88] Copyright 2009 American Chemical Society.

Another interesting phase is the stoichiometric $\mathrm{TiO}_{2}$ rect phase, showing an incommensurate rectangular unit cell of size $3.8 \AA \times 3.0 \AA$. STM revealed also that the apparent height of the rect$\mathrm{TiO}_{2}$ islands can be only explained by a multilayer sequence, with oxygen atoms at the interface with Pt occupying only top and bridge sites, an arrangement similar to the one proposed for rect $\mathrm{VO}_{2}$ [89]. Recently, other reduced hexagonal phases $h(6 \times 6)$ and $h(9 \times 9)$ were discovered by annealing $z$ ' phases at high temperature [90].

\section{Two-dimensional films of other reducible oxides}

\subsection{Transition metal oxide two-dimensional films}

Indeed, most transition metals, due to their specific electronic structure, can have different oxidation states and can form oxides which are reducible. Within the wide number of studies done in the field of two-dimensional reducible transition metal oxide films, we will here focus on those reporting aspects strictly related to reducibility and we will limit to the strictly two-dimensional case, i.e. to films with thickness of the order or below $1 \mathrm{~nm}$.

A very interesting example of a study of this kind is represented by the work by Li et al. on manganese oxide two-dimensional films [91]. By STM, LEED and XPS analyses different low dimensionality phases were identified in films of approximately 1 ML thickness as a function of the 
oxygen chemical potential during preparation on a $\operatorname{Pd}(100)$ substrate. Figure 12 summarizes the obtained results. Among the observed structures, some represent the two-dimensional limit of bulk truncated structures, like the hexagonal structure observed under mildly oxidizing condition, which recalls the $\mathrm{MnO}(111)$ structure. Most of them on the contrary do not resemble any known manganese oxide phase and they are often found in coexistence on the Pd surface [92].

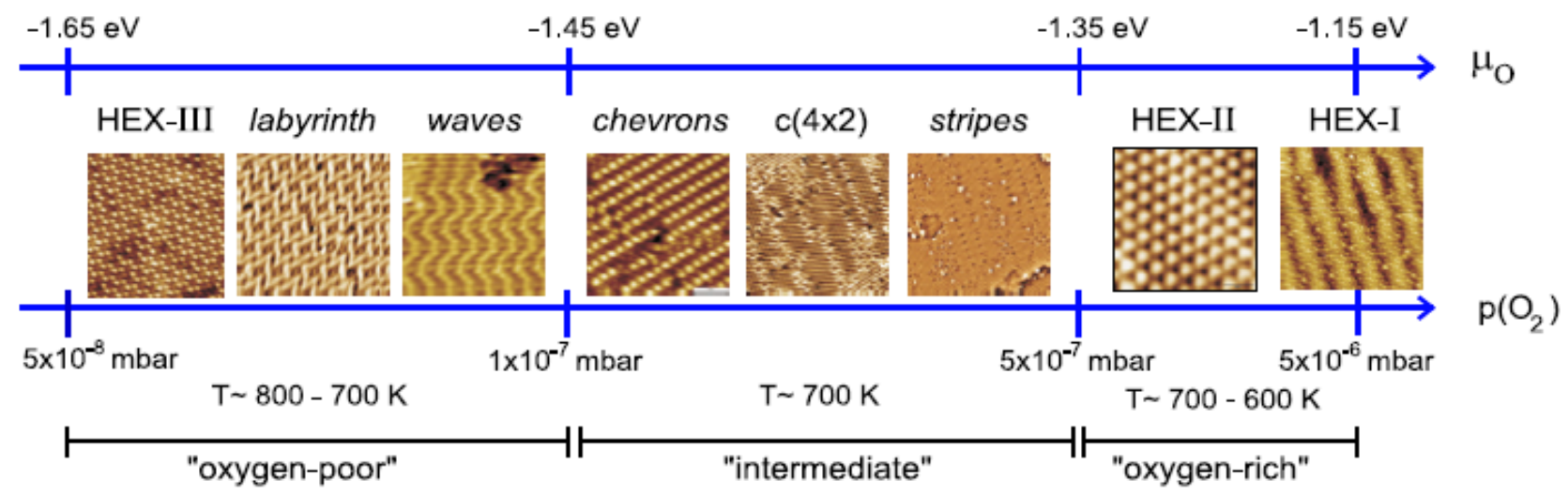

Fig. 12: Schematic phase diagram of the two-dimensional Mn oxides, presented as a function of the oxygen pressure $p(\mathrm{O} 2)$ and of the oxygen chemical potential $\mu_{\mathrm{O}}$. The nominal coverage of $\mathrm{Mn}$ on $\mathrm{Pd}(100)$ is $0.75 \mathrm{ML}$. (C) IOP Publishing. Reproduced with permission from Li et al. [91]. All rights reserved.

Also vanadium cations in vanadium oxide can have different oxidation states (from $2+$ to $5+$ ), giving a wide variety of phases. The most important ones are $\mathrm{V}_{2} \mathrm{O}_{5}, \mathrm{VO}_{2}, \mathrm{~V}_{2} \mathrm{O}_{3}$ and $\mathrm{VO}$, each one having a different crystal structure and showing a variety of physical and chemical properties [92]. Furthermore, mixed valence oxides can also be formed, with the cations in two possible oxide states, like for example $\mathrm{V}^{5+}$ and $\mathrm{V}^{4+}$ in $\mathrm{V}_{6} \mathrm{O}_{13}$. Of peculiar interest is the crystal structure of $\mathrm{V}_{2} \mathrm{O}_{5}$ (layered orthorhombic), which is essentially composed of zigzag double chains of square $\mathrm{VO}_{5}$ pyramidal units sharing edges and running along the $\mathrm{b}$ direction. The $\mathrm{VO}_{5}$ pyramid has the vanadium atom in the centre, four oxygen atoms in the basal plane and a vanadyl-type oxygen atom at the apex (see also inset of figure 14d). The layers of chains are stacked along the $\left[\begin{array}{lll}0 & 0 & 1\end{array}\right]$ (c) direction. The resulting solid is composed of distorted tetrahedrally coordinated $\mathrm{VO}_{6}$ unit. $\mathrm{The} \mathrm{VO}_{6}$ unit is also present in the tetrahedral rutile and monoclinic phases of $\mathrm{VO}_{2}$ which are stable below and above $\mathrm{T}=340 \mathrm{~K}$ respectively, while the $\mathrm{V}_{2} \mathrm{O}_{3}$ phase has a corundum structure above $160 \mathrm{~K}$. All these structures can be found in ultrathin films grown either on oxides or on metals, but other phases can also be stabilised by the interaction with the substrate $[89,92]$.

A systematic work was carried out on vanadium oxide nanostructures and films deposited on $\mathrm{Rh}(111)$ by Netzer and co-workers. The experimental results were supported by ab initio DFT calculations in order to obtain complete information the structure and on the thermodynamics of the different phases obtained [89,93-96]. A phase diagram of the vanadium oxide nanostructures on $\mathrm{Rh}(111)$ is reported in figure 13. Concentrating on the two-dimensional phases, it was found that $(\sqrt{7}$ $\times \sqrt{ } 7) \mathrm{R} 19.1^{\circ}$ or $(\sqrt{ } 13 \times \sqrt{ } 13) \mathrm{R} 13.8^{\circ}$ structures can be formed under highly oxidative conditions, with $\mathrm{P}_{\mathrm{O} 2}=2 \times 10^{-7}$ mbar and by keeping the substrate temperature at $670 \mathrm{~K}$. 


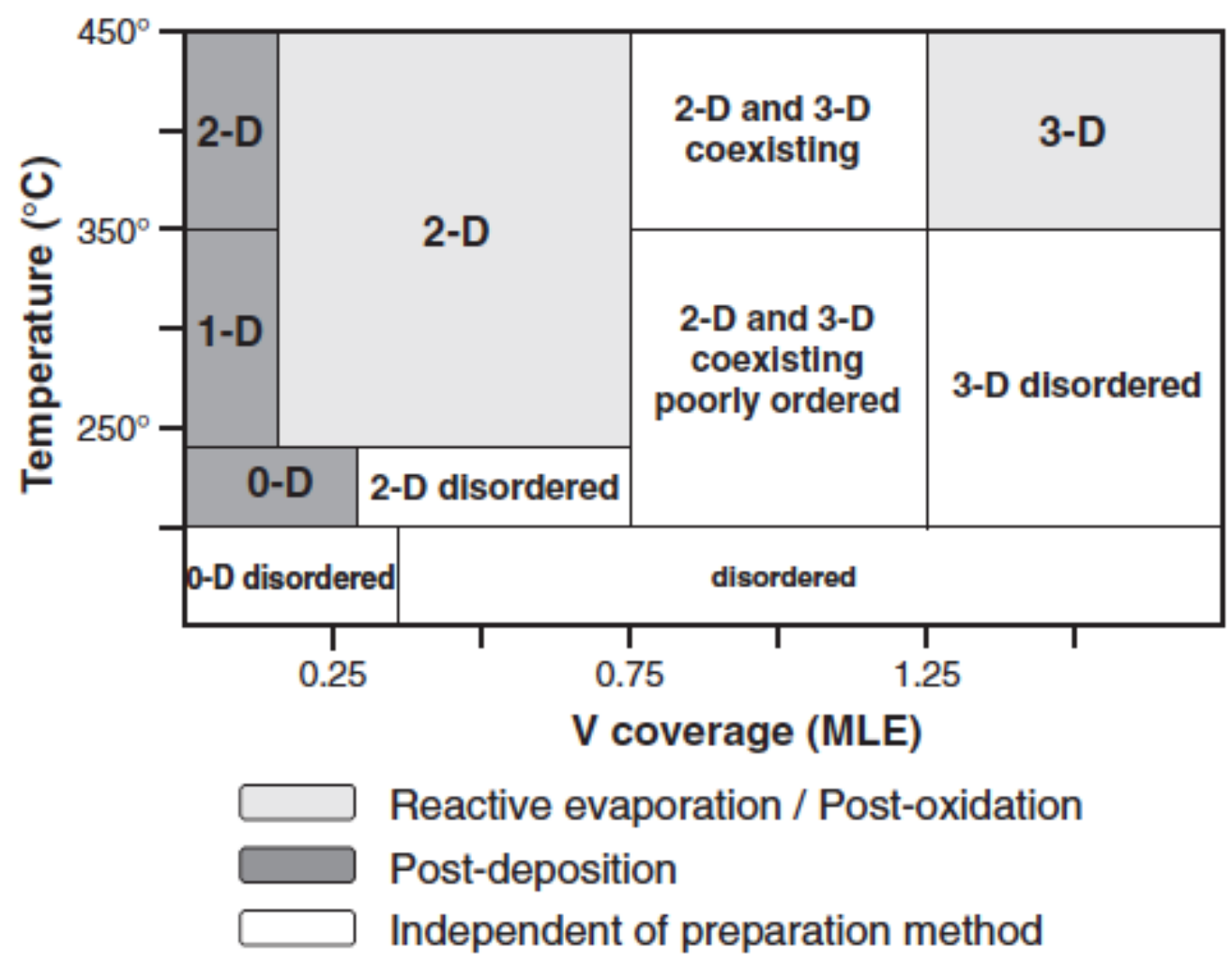

Fig. 13: Phase diagram of vanadium oxide nanostructures on $\mathrm{Rh}(111)$ as a function of vanadium coverage and of substrate temperature. (C) IOP Publishing. Reproduced with permission from J. Schoiswohl et al. [89]. All rights reserved.

As obtained by careful analysis of STM images and by DFT calculations, the $(\sqrt{ } 7 \times \sqrt{ } 7) \mathrm{R} 19.1^{\circ}$ nanolayer consists on a $\mathrm{V}_{3} \mathrm{O}_{9}$ oxide phase with $\mathrm{VO}_{5}$ square pyramids as building blocks. The same holds for the $(\sqrt{ } 13 \times$ $\sqrt{13) \mathrm{R}} 13.8^{\circ}$ phase, which has a $\mathrm{V}_{6} \mathrm{O}_{18}$ stoichiometry.

By exposing the film to reducing conditions (i. e. to annealing in UHV or in hydrogen atmosphere) reduced two-dimensional phases can be obtained with $\mathrm{V}_{11} \mathrm{O}_{23}, \mathrm{~V}_{13} \mathrm{O}_{21}, \mathrm{~V}_{2} \mathrm{O}_{3}$ and $\mathrm{VO}$ stoichiometry. The reduction process occurs essentially by removing the vanadyl groups.

Zero-dimensional structures could also be obtained by evaporation of small quantities (less than $0.2 \mathrm{ML}$ ) of vanadium on $\mathrm{O}(2 \times 1)-\mathrm{Rh}(111)$ and by flashing at $250^{\circ} \mathrm{C}$ in UHV. The obtained structures are identical planar star-shaped $\mathrm{V}_{6} \mathrm{O}_{12}$ molecules [96]. It was shown also that under high substrate temperature the clusters can diffuse and assemble in 2 -D overlayers with well determined phases, like $(5 \times 5)$ or the $(5 \times 3 \sqrt{3})$-rect. The different phases are obtained either in oxidizing or in reducing conditions [89]. 

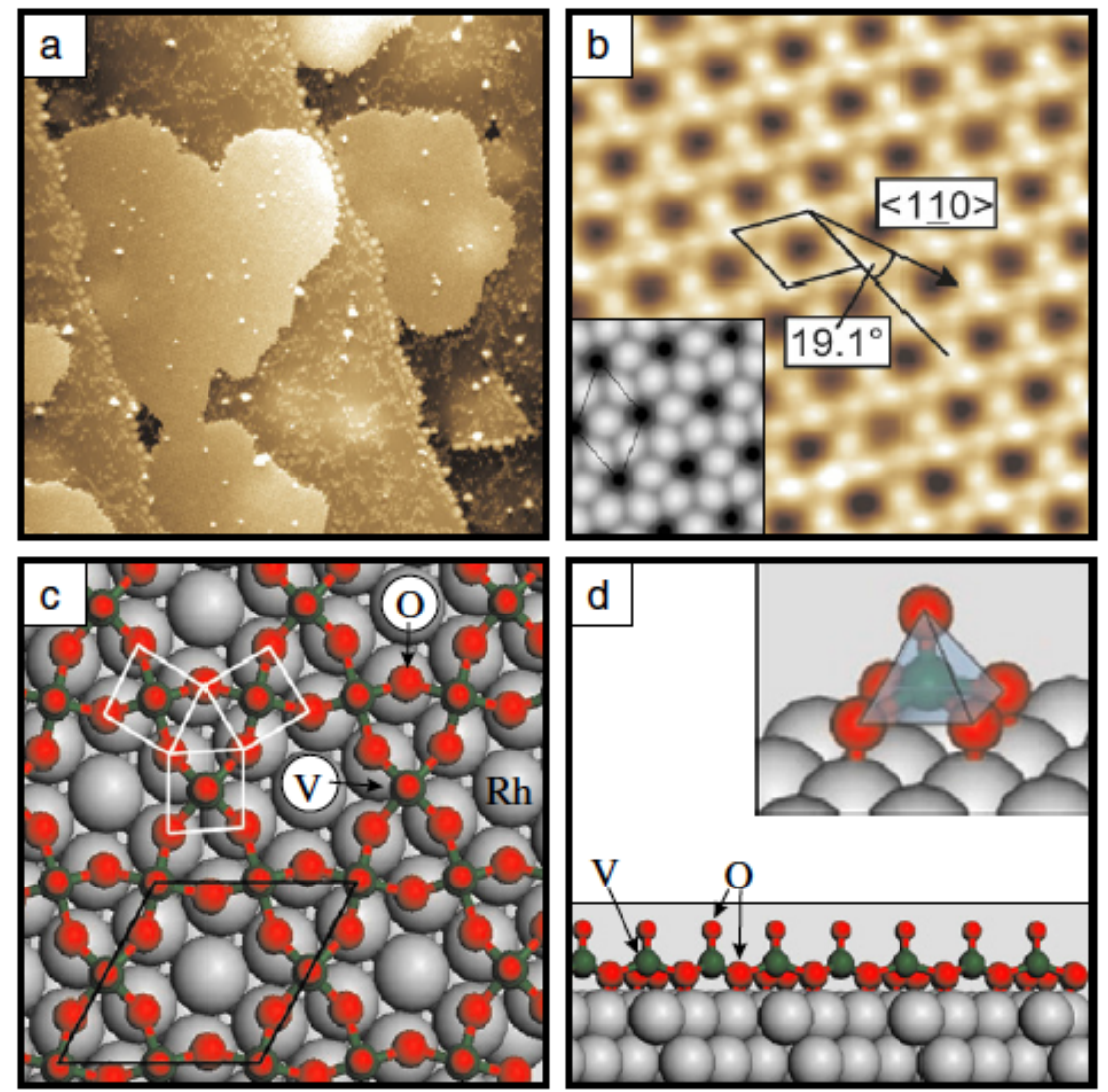

Fig. 14: a) Large scale $\left(100 \times 100 \mathrm{~nm}^{2}\right)$ and b) high resolution STM images of the $(\sqrt{ } 7 \mathrm{X} \sqrt{7}) \mathrm{R} 19.1^{\circ}$ vanadium oxide nanolayer on $\mathrm{Rh}(111)$. Inset simulated STM image obtained by DFT calculations. c) Top view and d) side view of the structural model obtained by DFT. Inset: the $\mathrm{VO}_{5}$ square pyramid constituting the building block of the film. (C) IOP Publishing. Reproduced with permission from J. Schoiswohl et al. [89]. All rights reserved.

Another interesting example is the growth of $\mathrm{V}_{2} \mathrm{O}_{\mathrm{y}}(\mathrm{y} \approx 5)$ and $\mathrm{V}_{2} \mathrm{O}_{5}$ on $\mathrm{Au}(111)$ reported by the Freund group $[97,98]$. The films were obtained by physical vapour deposition of vanadium, subsequent oxidation under 50 mbar of oxygen at $670 \mathrm{~K}$ and annealing in UHV at $470 \mathrm{~K}$. The high oxygen pressure used allowed to obtain a high oxidation state $\left(\mathrm{V}^{5+}\right)$ even for films thicker than 1 MLE (1 MLE corresponding to the same number of $\mathrm{V}$ atoms as one layer of $\mathrm{Au}(111)$ ), at variance with previous studies, where the standard reactive deposition and post-oxidation procedures gave $\mathrm{V}^{2+}, \mathrm{V}^{3+}$ or $\mathrm{V}^{4+}$ states (see for example ref. 89,93,99-101). At low coverage, from 0.26 to $1.04 \mathrm{MLE}$, two different coincidence monolayer structures could be observed by STM and LEED, which are determined by the interaction with the $\mathrm{Au}(111)$ substrate. The first structure has a rectangular unit cell, with size $3.6 \AA \times 15 \AA$, while the second one (observed at $0.52 \mathrm{MLE}$ of V/Au(111) which correspond to one full layer of oxide film), has a $3.6 \AA \times 10.8 \AA\left(\alpha=60^{\circ}\right)$ oblique unit cell. In analogy with the case of vanadium oxide monolayers on $\operatorname{Rh}(111)$ [89,93-96], it was supposed that the full monolayer film consisted of $\mathrm{VO}_{5}$ pyramid building blocks sharing corners and edges at their bases, and on the basis of the XPS and XANES measurements it was also shown that the oxidation state in the V cations is close to $\mathrm{V}^{5+}$, characteristics of $\mathrm{V}_{2} \mathrm{O}_{5}$. Increasing the coverage again to $1.05 \mathrm{MLE}$, a different structure was observed, which was found to be similar to $\mathrm{V}_{6} \mathrm{O}_{13}$ with (001) orientation, while for higher coverage $\mathrm{V}_{2} \mathrm{O}_{5}$ islands were formed, extending in size and giving rise eventually to $\mathrm{V}_{2} \mathrm{O}_{5}(001)$ films containing a low number of point defects. These films were composed of large $(20 \mathrm{~nm}$ size $)$ single crystal domains with some azimuthal disorder (figure 15) [97]. 

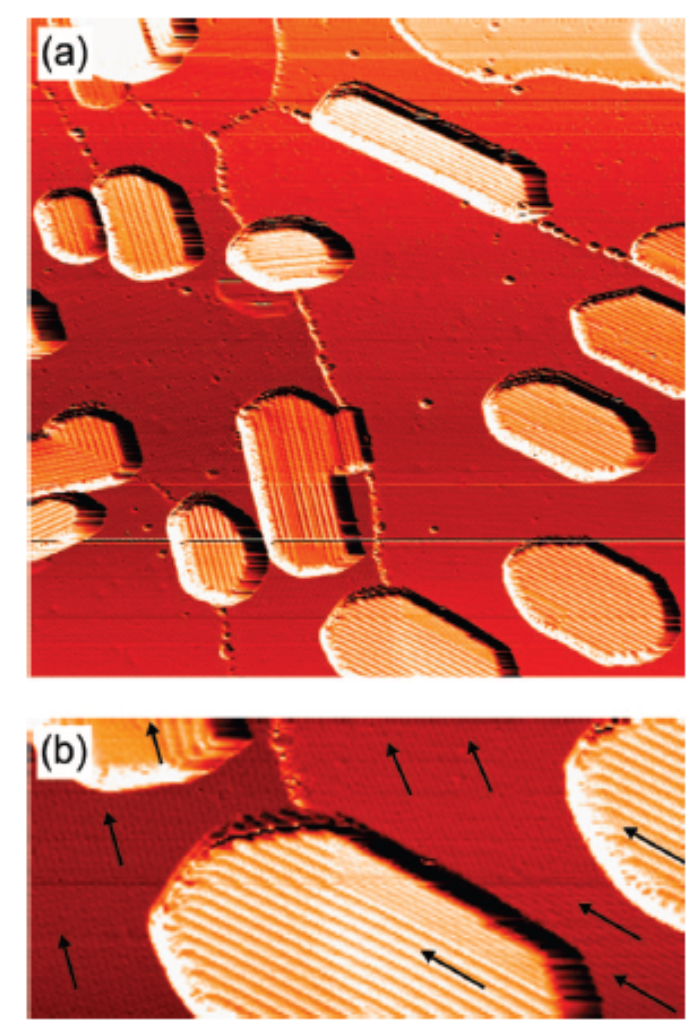

Fig. 15: STM images of a) $100 \times 100 \mathrm{~nm}^{2}$, b) $44 \times 20 \mathrm{~nm}^{2}$ of a film formed by the oxidation of 1.56 MLE V/Au(111). The images show the presence of $\mathrm{V}_{2} \mathrm{O}_{5}(100)$ islands growing on $\mathrm{V}_{6} \mathrm{O}_{13}(001)$ film. Reprinted with permission from $\mathrm{S}$. Guimond et al. [97] Copyright 2008 American Chemical Society.

\subsection{Rare earth oxide two-dimensional films}

In analogy with cerium oxide also in other rare earth oxides (REOs), like praseodymium, terbium and samarium oxide the cations can have different oxidation states, and the oxides can be defined as reducible. For samarium oxide the most stable oxidation state is $\mathrm{Sm}_{2} \mathrm{O}_{3}$, which can form different structural phases. Samarium oxide is the only REO which can also form a monoxide, SmO, with a rock-salt structure, stable under reducing conditions. The most stable valence state for terbium is $3+$, leading to the $\mathrm{Tb}_{2} \mathrm{O}_{3}$ phase, however also the dioxide $\mathrm{TbO}_{2}$, as well as intermediate phases like $\mathrm{Tb}_{4} \mathrm{O}_{7}$, can form. Praseodymium can have the $2+, 3+$ and $4+$ oxidation states and the most stable oxides are $\operatorname{Pr}_{2} \mathrm{O}_{3}, \operatorname{PrO}_{2}$ and $\operatorname{Pr}_{6} \mathrm{O}_{11}$. The sesquioxides are typically stable in the c-type bixbyite structure, at variance with cerium oxide, for which the hexagonal A-type phase is favoured in the $\mathrm{Ce}_{2} \mathrm{O}_{3}$ stoichiometry.

Some studies report the growth of REO in the form of ultrathin films on metallic substrates and point out interesting aspects related to those observed in cerium oxide ultrathin films. Temperature programmed desorption (TPD) allows to monitor oxygen release in these REO films, while in the case of cerium oxide the release is considered to be too fast to be monitored [102,103].

Samarium oxide in the form of an ultrathin film has been shown to form by controlled oxidation of surface SmRh and SmRu surface alloys, in turn obtained by heating metallic Sm films deposited on $\mathrm{Rh}(100)$ and $\mathrm{Ru}(0001)$ surfaces respectively, leading to a $\mathrm{SmO}_{\mathrm{x}}$ phase [102-104]. On both substrates specific sites for $\mathrm{CO}$ absorption have been shown to form at the perimeter of the samarium oxide ultrathin islands, due to the interaction with the underlying metal [102,103]. A 
more recent study by Jhang et al. investigated samarium oxide films grown on a $\operatorname{Pt}(111)$ substrate by reactive deposition at $600 \mathrm{~K}$ followed by annealing in $\mathrm{O}_{2}\left(\mathrm{P} \sim 10^{-7} \mathrm{mbar}\right)$ at $1000 \mathrm{~K}$ [105]. In close analogy with cerium oxide films grown in similar conditions, the LEED pattern for submonolayer coverage shows a $(1.37 \times 1.37)$ structure. Interestingly, for coverages between 1 and 3 ML the LEED pattern shows additional faint spots in the so called quasi- $(3 \times 3)$ superstructure, very similar to the one observed in reduced ultrathin cerium oxide phases on $\operatorname{Pt}(111)$ (figure 16) $[17,29]$. The authors ascribe this features to a $\mathrm{Sm}_{2} \mathrm{O}_{3}(111)$ phase with a defective fluorite structure, in which the oxygen vacancies are randomly distributed within the crystal, and to the formation of a 8:11 coincidence with the underlying Pt. A similar origin may be invoked also for the LEED pattern of reduced cerium oxide films, although in the latter case a similar coincidence may be expected also when the films are oxidized, and the reasons for its appearance only when the films are reduced are not clear. Reduction by thermal treatments in UHV at $1000 \mathrm{~K}$ for $30 \mathrm{~min}$ of the $\mathrm{Sm}_{2} \mathrm{O}_{3}$ films lead to the coexistence of $\mathrm{Sm}_{2} \mathrm{O}_{3}(111)$ phase and of a $\mathrm{SmO}(100)$ phase, giving a superstructure rotated by $30^{\circ}$ with respect to the (111) spots in the LEED pattern [105]. The reversibility of the structural and morphological modifications is observed also in this case [105].
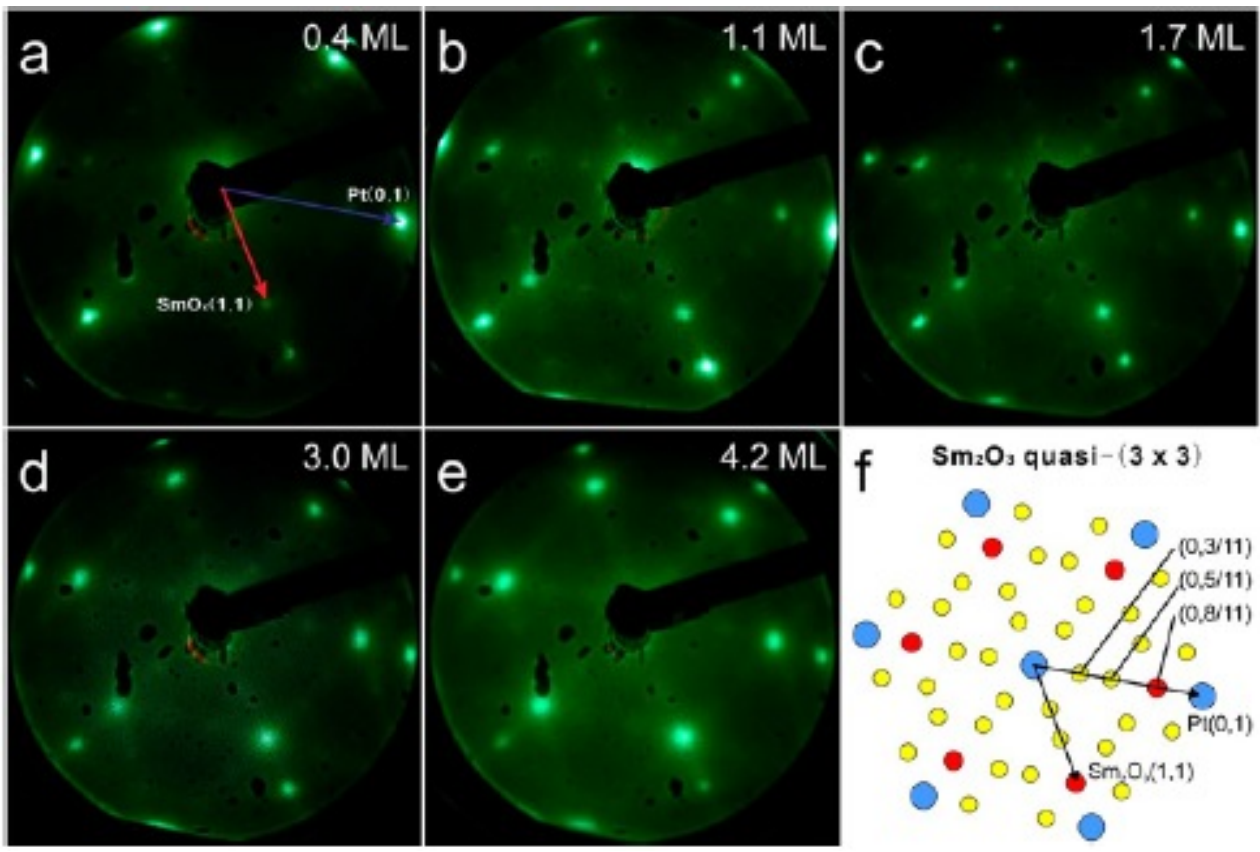

Fig.16: LEED patterns obtained after growing $\mathrm{Sm}_{2} \mathrm{O}_{3}(111)$ films on $\mathrm{Pt}(111)$ to the coverages indicated followed by annealing in $7 \times 10^{-7}$ mbar of $\mathrm{O}_{2}$ at $1000 \mathrm{~K}$ for $10 \mathrm{~min}$ : (a) $0.4 \mathrm{ML}$ of $\mathrm{Sm}_{2} \mathrm{O}_{3}$ shows a hexagonal $(1.37 \times 1.37)$ superstructure in registry with the $\operatorname{Pt}(111)(1 \times 1)$ spots, $\mathrm{E}=58 \mathrm{eV},(\mathrm{b}) 1.1 \mathrm{ML}, \mathrm{E}=48 \mathrm{eV}$, (c) $1.7 \mathrm{ML}, \mathrm{E}=56 \mathrm{eV}$, (d) 3.0 ML, E $=52 \mathrm{eV}$ exhibit a quasi- $(3 \times 3)$ superstructure, $(\mathrm{e}) 4.2 \mathrm{ML}, \mathrm{E}=56 \mathrm{eV}$; the quasi- $(3 \times 3)$ becoming blurry, and (f) shows a schematic representation of the quasi- $(3 \times 3)$ pattern that is determined from FFT analysis of a structural model of superposed, hexagonal $\mathrm{Sm}$ and Pt lattices that form a hexagonal $(8 \times 8)$ coincidence lattice with respect to the Sm lattice, i.e. $(11 \times 11)$ with respect to the Pt lattice. Reprinted with permission from Jhang et al. [105] Copyright 2013 American Chemical Society.

Terbium oxide films were prepared with similar methods, i. e. using reactive deposition and post growth annealing in $\mathrm{O}_{2}$ [106]. The LEED pattern up to $4 \mathrm{ML}$ thickness shows the $(1.32 \times 1.32)$ structure, compatible with the terbium oxide lattice parameter of the $\mathrm{Tb}_{2} \mathrm{O}_{3}$ phase in a fluorite structure with disordered oxygen vacancies in close analogy with the case of samarium oxide [107]. In this case however diffraction from possible coincidence superlattices could not be observed. The 
films could not be oxidized by using thermal treatments in $\mathrm{O}_{2}$ at $\mathrm{P} \sim 7 \times 10^{-7}$ mbar and temperatures from 95 to $1000 \mathrm{~K}$, while plasma-generated atomic oxygen was shown to be effective in oxidizing a film at $300 \mathrm{~K}$ to $\mathrm{TbO}_{2}$ and in generating weakly bound surface $\mathrm{O}$ species. The reduced $\mathrm{Tb}_{2} \mathrm{O}_{3}$ phase could be re-obtained by annealing $\mathrm{TbO}_{2}$ in vacuum at $1000 \mathrm{~K}$ [106].

Praseodymium oxide has been studied only in the form of relatively thick films on $\mathrm{Si}(111)$ substrates [107-109]. As for terbium oxide thin films, also in this case, an oxidizing treatment in oxygen plasma was shown to be necessary to oxidize the $\mathrm{Pr}_{2} \mathrm{O}_{3}$ phase to the $\mathrm{PrO}_{2}$ fluorite phase [107]. UHV thermal treatments to reduce the $\mathrm{PrO}_{2}$ phase have been shown to give origin to a phase including a mixture of $\operatorname{Pr}_{6} \mathrm{O}_{11}$ and $\operatorname{Pr}_{5} \mathrm{O}_{9}$, the latter being unstable in the bulk phase [109].

\section{Conclusions}

The studies discussed in this chapter show that reducible oxides at two dimensionality may show important modifications of their properties, and indeed also of the reversible reduction and oxidation processes. Ultrathin films, typically supported on metal substrates, at different degree of reduction show new structural and chemical phases, often unstable in the bulk, which have been deeply characterized by surface science techniques, combined with the extremely important support of theoretical modeling. In some cases the different phases can be reversibly transformed one into the other by reducing and oxidizing treatments. The studies point out interesting challenging aspects, on which future studies might be focused, such as for example the stabilization of phases with less stable surface orientation, or more complex systems such as ternary two-dimensional compounds or mixed oxide phases. We believe that investigations following these lines may open up unexpectedly interesting aspects within the field of reducible oxide based materials.

\section{Acknowledgements}

The authors gratefully acknowledge the support by the Italian MIUR through the FIRB Project RBAP115AYN "Oxides at the nanoscale: multifunctionality and applications" and by the COST Action CM1104 "Reducible oxide chemistry, structure and functions".

\section{References}

1. Trovarelli A, Fornasiero P (2013) Catalysis by Ceria and Related Materials. Catalytic Science, 2nd edn. Imperial College Pr., London

2. Celardo I, Pedersen JZ, Traversa E, Ghibelli L (2011) Pharmacological potential of cerium oxide nanoparticles. Nanoscale 3 (4):1411-1420

3. Waser R, Dittmann R, Staikov G, Szot K (2009) Redox-Based Resistive Switching Memories - Nanoionic Mechanisms, Prospects, and Challenges. Adv Mater 21 (25-26):2632 
4. Migani A, Vayssilov GN, Bromley ST, Illas F, Neyman KM (2010) Dramatic reduction of the oxygen vacancy formation energy in ceria particles: a possible key to their remarkable reactivity at the nanoscale. $\mathrm{J}$ Mater Chem 20 (46):10535-10546

5. Cafun JD, Kvashnina KO, Casals E, Puntes VF, Glatzel P (2013) Absence of Ce3+ Sites in Chemically Active Colloidal Ceria Nanoparticles. Acs Nano 7 (12):10726-10732

6. Carrettin S, Concepcion P, Corma A, Nieto JML, Puntes VF (2004) Nanocrystalline CeO2 increases the activity of an for CO oxidation by two orders of magnitude. Angew Chem Int Edit 43 (19):2538-2540

7. Vayssilov GN, Lykhach Y, Migani A, Staudt T, Petrova GP, Tsud N, Skala T, Bruix A, Illas F, Prince KC, Matolin V, Neyman KM, Libuda J (2011) Support nanostructure boosts oxygen transfer to catalytically active platinum nanoparticles. Nat Mater 10 (4):310-315

8. Tauster SJ, Fung SC, Garten RL (1978) Strong Metal-Support Interactions - Group-8 Noble-Metals Supported on Tio2. J Am Chem Soc 100 (1):170-175

9. Bevan DJM (1955) Ordered intermediate phases in the system CeO2-Ce2O3. J Inorg Nucl Chem $1: 49$

10. Skorodumova NV, Simak SI, Lundqvist BI, Abrikosov IA, Johansson B (2002) Quantum origin of the oxygen storage capability of ceria. Phys Rev Lett 89 (16):166601

11. Conesa JC (1995) Computer Modeling of Surfaces and Defects on Cerium Dioxide. Surf Sci 339 (3):337-352

12. Hardacre C, Ormerod RM, Lambert RM (1994) Platinum-Promoted Catalysis by Ceria - a Study of Carbon-Monoxide Oxidation over Pt(111)/CeO2. J Phys Chem-Us 98 (42):10901-10905

13. Schierbaum KD (1998) Ordered ultra-thin cerium oxide overlayers on Pt(111) single crystal surfaces studied by LEED and XPS. Surf Sci 399 (1):29-38-X

14. Mullins DR, Radulovic PV, Overbury SH (1999) Ordered cerium oxide thin films grown on Ru(0001) and $\mathrm{Ni}(111)$. Surf Sci 429 (1-3):186-198

15. Eck S, Castellarin-Cudia C, Surnev S, Ramsey MG, Netzer FP (2002) Growth and thermal properties of ultrathin cerium oxide layers on Rh(111). Surf Sci 520 (3):173-185

16. Wilson EL, Chen Q, Brown WA, Thornton G (2007) CO adsorption on the model catalyst $\mathrm{Pd} / \mathrm{CeO} 2-$ x(111)/Rh(111). J Phys Chem C 111 (38):14215-14222

17. Luches P, Pagliuca F, Valeri S (2011) Morphology, Stoichiometry, and Interface Structure of CeO2 Ultrathin Films on Pt(11). J Phys Chem C 115 (21):10718-10726

18. Staudt T, Lykhach Y, Hammer L, Schneider MA, Matolin V, Libuda J (2009) A route to continuous ultra-thin cerium oxide films on $\mathrm{Cu}(111)$. Surf Sci 603 (23):3382-3388

19. Xiao WD, Guo QL, Wang EG (2003) Transformation of CeO2(111) to Ce2O3(0001) films. Chem Phys Lett 368 (5-6):527-531

20. Lu JL, Gao HJ, Shaikhutdinov S, Freund HJ (2006) Morphology and defect structure of the CeO2(111) films grown on $\mathrm{Ru}(0001)$ as studied by scanning tunneling microscopy. Surf Sci 600 (22):5004-5010

21. Grinter DC, Ithnin R, Pang CL, Thornton G (2010) Defect Structure of Ultrathin Ceria Films on Pt(111): Atomic Views from Scanning Tunnelling Microscopy. J Phys Chem C 114 (40):17036-17041 
22. Flege JI, Kaemena B, Gevers S, Bertram F, Wilkens T, Bruns D, Batjer J, Schmidt T, Wollschlager J, Falta J (2011) Silicate-free growth of high-quality ultrathin cerium oxide films on Si(111). Phys Rev B 84 (23):235418

23. Pagliuca F, Luches P, Valeri S (2013) Interfacial interaction between cerium oxide and silicon surfaces. Surf Sci 607:164-169

24. Putna ES, Bunluesin T, Fan XL, Gorte RJ, Vohs JM, Lakis RE, Egami T (1999) Ceria films on zirconia substrates: models for understanding oxygen-storage properties. Catal Today 50 (2):343-352

25. vanWijck MAAM, Verhoeven MAJ, Reuvekamp EMCM, Gerritsma GJ, Blank DHA, Rogalla H (1996) $\mathrm{CeO} 2$ as insulation layer in high T-c superconducting multilayer and crossover structures. Appl Phys Lett 68 (4):553-555

26. Overbury SH, Huntley DR, Mullins DR, Ailey KS, Radulovic PV (1997) Surface studies of model supported catalysts: NO adsorption on Rh/CeO2(001). J Vac Sci Technol A 15 (3):1647-1652

27. Hardacre C, Roe GM, Lambert RM (1995) Structure, Composition and Thermal-Properties of Cerium Oxide-Films on Platinum(111). Surf Sci 326 (1-2):1-10

28. Berner U, Schierbaum KD (2002) Cerium oxides and cerium-platinum surface alloys on Pt(111) singlecrystal surfaces studied by scanning tunneling microscopy. Phys Rev B 65 (23):235404

29. Luches P, Pagliuca F, Valeri S (2014) Structural and morphological modifications of thermally reduced cerium oxide ultrathin epitaxial films on Pt(111). Phys Chem Chem Phys 16 (35):18848-18857

30. Matolin V, Libra J, Matolinova I, Nehasil V, Sedlacek L, Sutara F (2007) Growth of ultra-thin cerium oxide layers on $\mathrm{Cu}(111)$. Appl Surf Sci 254 (1):153-155

31. Yang F, Graciani J, Evans J, Liu P, Hrbek J, Sanz JF, Rodriguez JA (2011) CO Oxidation on Inverse $\mathrm{CeOx} / \mathrm{Cu}(111)$ Catalysts: High Catalytic Activity and Ceria-Promoted Dissociation of O-2. J Am Chem Soc 133 (10):3444-3451

32. Ma SG, Rodriguez J, Hrbek J (2008) STM study of the growth of cerium oxide nanoparticles on $\mathrm{Au}(111)$. Surf Sci 602 (21):3272-3278

33. Škoda M, Libra J, Šutara F, Tsud N, Skála T, Sedláček L, Cháb V, Prince KC, Matolín V (2007) A resonant photoemission study of the Ce and Ce-oxide/Pd(lllll) interfaces. Surf Sci 601 (21):4958-4965

34. Grinter DC, Yim CM, Pang CL, Santos B, Mentes TO, Locatelli A, Thornton G (2013) Oxidation State Imaging of Ceria Island Growth on Re(0001). J Phys Chem C 117 (32):16509-16514

35. Suchorski Y, Wrobel R, Becker S, Weiss H (2008) CO Oxidation on a CeOx/Pt(111) Inverse Model Catalyst Surface: Catalytic Promotion and Tuning of Kinetic Phase Diagrams. J Phys Chem C 112 (50):20012-20017

36. Eck S, Castellarin-Cudia C, Surnev S, Prince KC, Ramsey MG, Netzer FP (2003) Adsorption and reaction of $\mathrm{CO}$ on a ceria-Rh(1 11 1) "inverse model catalyst" surface. Surf Sci 536 (1-3):166-176

37. Rodriguez JA, Graciani J, Evans J, Park JB, Yang F, Stacchiola D, Senanayake SD, Ma S, Pérez M, Liu P, Sanz JF, Hrbek J (2009) Water-Gas Shift Reaction on a Highly Active Inverse CeOx/Cu(111) Catalyst: Unique Role of Ceria Nanoparticles. Angewandte Chemie International Edition 48 (43):8047-8050 
38. Dvorak F, Stetsovych O, Steger M, Cherradi E, Matolinova I, Tsud N, Skoda M, Skala T, Myslivecek J, Matolin V (2011) Adjusting Morphology and Surface Reduction of CeO2(111) Thin Films on Cu(111). J Phys Chem C 115 (15):7496-7503

39. Luches P, Pagliuca F, Valeri S, Boscherini F (2013) Structure of Ultrathin CeO2 Films on Pt(111) by Polarization-Dependent X-ray Absorption Fine Structure. J Phys Chem C 117 (2):1030-1036

40. Szabova L, Stetsovych O, Dvorak F, Camellone MF, Fabris S, Myslivecek J, Matolin V (2012) Distinct Physicochemical Properties of the First Ceria Monolayer on Cu(111). J Phys Chem C 116 (11):6677-6684

41. Spiel C, Blaha P, Suchorski Y, Schwarz K, Rupprechter G (2011) CeO2/Pt(111) interface studied using first-principles density functional theory calculations. Phys Rev B 84 (4):045412

42. Nilius N, Kozlov SM, Jerratsch JF, Baron M, Shao X, Vines F, Shaikhutdinov S, Neyman KM, Freund HJ (2012) Formation of One-Dimensional Electronic States along the Step Edges of CeO2(111). Acs Nano 6 (2):1126-1133

43. Torbrugge S, Cranney M, Reichling M (2008) Morphology of step structures on $\mathrm{CeO}(2)(111)$. Appl Phys Lett 93 (7):073112

44. Jerratsch JF, Shao X, Nilius N, Freund HJ, Popa C, Ganduglia-Pirovano MV, Burow AM, Sauer J (2011) Electron Localization in Defective Ceria Films: A Study with Scanning-Tunneling Microscopy and DensityFunctional Theory. Phys Rev Lett 106 (24):246801

45. Esch F, Fabris S, Zhou L, Montini T, Africh C, Fornasiero P, Comelli G, Rosei R (2005) Electron localization determines defect formation on ceria substrates. Science 309 (5735):752-755

46. Ganduglia-Pirovano MV, Da Silva JLF, Sauer J (2009) Density-Functional Calculations of the Structure of Near-Surface Oxygen Vacancies and Electron Localization on CeO2(111). Phys Rev Lett 102 (2):026101

47. Loschen C, Bromley ST, Neyman KM, Illas F (2007) Understanding ceria nanoparticles from firstprinciples calculations. J Phys Chem C 111 (28):10142-10145

48. Kaemena B, Senanayake SD, Meyer A, Sadowski JT, Falta J, Flege JI (2013) Growth and Morphology of Ceria on Ruthenium (0001). J Phys Chem C 117 (1):221-232

49. Pfau A, Schierbaum KD (1994) The Electronic-Structure of Stoichiometric and Reduced Ceo2 Surfaces an Xps, Ups and Hreels Study. Surf Sci 321 (1-2):71-80

50. Matolin V, Libra J, Skoda M, Tsud N, Prince KC, Skala T (2009) Methanol adsorption on a $\mathrm{CeO} 2(111) / \mathrm{Cu}(111)$ thin film model catalyst. Surf Sci 603 (8):1087-1092

51. Senanayake SD, Stacchiola D, Evans J, Estrella M, Barrio L, Perez M, Hrbek J, Rodriguez JA (2010) Probing the reaction intermediates for the water-gas shift over inverse $\mathrm{CeOx} / \mathrm{Au}(111)$ catalysts. J Catal 271 (2):392-400

52. Castellarin-Cudia C, Surnev S, Schneider G, Podlucky R, Ramsey MG, Netzer FP (2004) Strain-induced formation of arrays of catalytically active sites at the metal-oxide interface. Surf Sci 554 (2-3):L120-L126

53. Duchon T, Dvorak F, Aulicka M, Stetsovych V, Vorokhta M, Mazur D, Veltruska K, Skala T, Myslivecek J, Matolinova I, Matolin V (2014) Ordered Phases of Reduced Ceria As Epitaxial Films on $\mathrm{Cu}(111)$. J Phys Chem C 118 (1):357-365 
54. Wilkens H, Schuckmann O, Oelke R, Gevers S, Reichling M, Schaefer A, Baumer M, Zoellner MH, Niu G, Schroeder T, Wollschlager J (2013) Structural transitions of epitaxial ceria films on Si(111). Phys Chem Chem Phys 15 (42):18589-18599

55. Stetsovych V, Pagliuca F, Dvorak F, Duchon T, Vorokhta M, Aulicka M, Lachnitt J, Schernich S, Matolinova I, Veltruska K, Skala T, Mazur D, Myslivecek J, Libuda J, Matolin V (2013) Epitaxial Cubic Ce2O3 Films via Ce-CeO2 Interfacial Reaction. J Phys Chem Lett 4 (6):866-871

56. Kozlov SM, Demiroglu I, Neyman KM, Bromley ST (2015) Reduced ceria nanofilms from structure prediction. Nanoscale 7 (10):4361-4366

57. Yang F, Choi Y, Agnoli S, Liu P, Stacchiola D, Hrbek J, Rodriguez JA (2011) CeO2 <-> CuOx Interactions and the Controlled Assembly of CeO2(111) and CeO2(100) Nanoparticles on an Oxidized $\mathrm{Cu}(111)$ Substrate. J Phys Chem C 115 (46):23062-23066

58. Stetsovych O, Beran J, Dvorak F, Masek K, Myslivecek J, Matolin V (2013) Polarity driven morphology of $\mathrm{CeO} 2(100)$ islands on $\mathrm{Cu}(111)$. Appl Surf Sci 285:766-771

59. Pan Y, Nilius N, Stiehler C, Freund HJ, Goniakowski J, Noguera C (2014) Ceria Nanocrystals Exposing Wide (100) Facets: Structure and Polarity Compensation. Adv Mater Interfaces 1 (9):1400404

60. Noguera C, Goniakowski J (2013) Polarity in Oxide Nano-objects. Chem Rev 113 (6):4073-4105

61. Maeda T, Kobayashi Y, Kishi K (1999) Growth of ultra-thin titanium oxide on $\mathrm{Cu}(100), \mathrm{Fe} / \mathrm{Cu}(100)$ and ordered ultra-thin iron oxide studied by low-energy electron diffraction and X-ray photoelectron spectroscopy. Surf Sci 436 (1-3):249-258

62. Passeggi MCG, Vergara LI, Mendoza SM, Ferron J (2002) Passivation and temperature effects on the oxidation process of titanium thin films. Surf Sci 507:825-831

63. Finetti P, Caffio M, Cortigiani B, Atrei A, Rovida G (2008) Mechanism of growth and structure of titanium oxide ultrathin films deposited on $\mathrm{Cu}(001)$. Surf Sci 602 (5):1101-1113

64. Atrei A, Bardi U, Rovida G (1997) Structure and composition of the titanium oxide layers formed by low-pressure oxidation of the Ni94Ti6(110) surface. Surf Sci 391 (1-3):216-225

65. Atrei A, Ferrari AM, Finetti P, Beni A, Rovida G (2009) LEED and DFT Study of the Quasihexagonal TiO2 Structure on Cu(001). J Phys Chem C 113 (45):19578-19584

66. Atrei A, Ferrari AM, Szieberth D, Cortigiani B, Rovida G (2010) Lepidocrocite-like structure of the TiO2 monolayer grown on $\mathrm{Ag}(100)$. Phys Chem Chem Phys 12 (37):11587-11595

67. Atrei A, Cortigiani B, Ferrari AM (2012) Epitaxial growth of TiO2 films with the rutile (110) structure on $\operatorname{Ag}(100)$. J Phys-Condens Mat 24 (44):445005

68. Orzali T, Casarin M, Granozzi G, Sambi M, Vittadini A (2006) Bottom-up assembly of single-domain titania nanosheets on (1x2)-Pt(110). Phys Rev Lett 97 (15):156101

69. McCavish ND, Bennett RA (2003) Ultra-thin film growth of titanium dioxide on W(100). Surf Sci 546 (1):47-56

70. Bennett RA, Mulley JS, Newton MA, Surman M (2007) Spectroscopy of ultrathin epitaxial rutile TiO2(110) films grown on W(100). J Chem Phys 127 (8):084707 
71. Pang CL, Grinter DC, Matharu J, Thornton G (2013) A Scanning Tunneling Microscopy Study of Ultrathin Film Rutile TiO2(110) Supported on W(100)-O(2 x 1). J Phys Chem C 117 (48):25622-25627

72. Oh WS, Xu C, Kim DY, Goodman DW (1997) Preparation and characterization of epitaxial titanium oxide films on Mo(100). J Vac Sci Technol A 15 (3):1710-1716

73. Chen MS, Goodman DW (2008) Ultrathin, ordered oxide films on metal surfaces. J Phys-Condens Mat 20 (26):264013

74. Guo Q, Oh WS, Goodman DW (1999) Titanium oxide films grown on Mo(110). Surf Sci 437 (1-2):4960

75. Lai X, Guo Q, Min BK, Goodman DW (2001) Synthesis and characterization of titania films on Mo(110). Surf Sci 487 (1-3):1-8

76. Chen MS, Goodman DW (2004) The structure of catalytically active gold on titania. Science 306 (5694):252-255

77. Matsumoto T, Batzill M, Hsieh S, Koel BE (2004) Fundamental studies of titanium oxide-Pt(100) interfaces - I. Stable high temperature structures formed by annealing TiOx films on Pt(100). Surf Sci 572 $(2-3): 127-145$

78. Papageorgiou AC, Cabailh G, Chen Q, Resta A, Lundgren E, Andersen JN, Thornton G (2007) Growth and reactivity of titanium oxide ultrathin films on Ni(110). J Phys Chem C 111 (21):7704-7710

79. Papageorgiou AC, Pang CL, Chen Q, Thornton G (2007) Low-dimensional, reduced phases of ultrathin TiO(2). Acs Nano 1 (5):409-414

80. Bennett RA, Poulston S, Stone P, Bowker M (1999) STM and LEED observations of the surface structure of TiO2(110) following crystallographic shear plane formation. Phys Rev B 59 (15):10341-10346

81. Dulub O, Hebenstreit W, Diebold U (2000) Imaging cluster surfaces with atomic resolution: The strong metal-support interaction state of Pt supported on TiO2(110). Phys Rev Lett 84 (16):3646-3649

82. Bennett RA, Pang CL, Perkins N, Smith RD, Morrall P, Kvon RI, Bowker M (2002) Surface structures in the SMSI state; Pd on (1 x 2) reconstructed TiO2(110). J Phys Chem B 106 (18):4688-4696

83. Matsumoto T, Batzill M, Hsieh S, Koel BE (2004) Fundamental studies of titanium oxide-Pt(100) interfaces - II. Influence of oxidation and reduction reactions on the surface structure of TiOx films on Pt(100). Surf Sci 572 (2-3):146-161

84. Boffa AB, Galloway HC, Jacobs PW, Benitez JJ, Batteas JD, Salmeron M, Bell AT, Somorjai GA (1995) The Growth and Structure of Titanium-Oxide Films on Pt(111) Investigated by Leed, Xps, Iss, and Stm. Surf Sci $326(1-2): 80-92$

85. Sedona F, Rizzi GA, Agnoli S, Xamena FXLI, Papageorgiou A, Ostermann D, Sambi M, Finetti P, Schierbaum K, Granozzi G (2005) Ultrathin TiOx films on Pt(111): A LEED, XPS, and STM investigation. J Phys Chem B 109 (51):24411-24426

86. Sedona F, Agnoli S, Granozzi G (2006) Ultrathin wagon-wheel-like TiOx phases on Pt(111): A combined low-energy electron diffraction and scanning tunneling microscopy investigation. J Phys Chem B $110(31): 15359-15367$ 
87. Finetti P, Sedona F, Rizzi GA, Mick U, Sutara F, Svec M, Matolin V, Schierbaum K, Granozzi G (2007) Core and valence band photoemission Spectroscopy of well-ordered ultrathin TiOx films on Pt(111). J Phys Chem C 111 (2):869-876

88. Barcaro G, Agnoli S, Sedona F, Rizzi GA, Fortunelli A, Granozzi G (2009) Structure of Reduced Ultrathin TiOx Polar Films on Pt(111). J Phys Chem C 113 (14):5721-5729

89. Schoiswohl J, Surnev S, Netzer FP, Kresse G (2006) Vanadium oxide nanostructures: from zero- to three-dimensional. J Phys-Condens Mat 18 (4):R1-R14

90. Barcaro G, Cavaliere E, Artiglia L, Sementa L, Gavioli L, Granozzi G, Fortunelli A (2012) Building Principles and Structural Motifs in TiOx Ultrathin Films on a (111) Substrate. J Phys Chem C 116 (24):13302-13306

91. Li F, Parteder G, Allegretti F, Franchini C, Podloucky R, Surnev S, Netzer FP (2009) Two-dimensional manganese oxide nanolayers on $\operatorname{Pd}(100)$ : the surface phase diagram. J Phys-Condens Mat 21 (13):134008

92. Surnev S, Ramsey MG, Netzer FP (2003) Vanadium oxide surface studies. Prog Surf Sci 73 (4-8):117165

93. Surnev S, Kresse G, Ramsey MG, Netzer FP (2001) Novel interface-mediated metastable oxide phases: Vanadium oxides on Pd(111). Phys Rev Lett 87 (8):086102

94. Schoiswohl J, Sock M, Eck S, Surnev S, Ramsey MG, Netzer FP, Kresse G (2004) Atomic-level growth study of vanadium oxide nanostructures on $\mathrm{Rh}(111)$. Phys Rev B 69 (15):155403

95. Schoiswohl J, Surnev S, Sock M, Eck S, Ramsey MG, Netzer FP, Kresse G (2005) Reduction of vanadium-oxide monolayer structures. Phys Rev B 71 (16):165437

96. Schoiswohl J, Kresse G, Surnev S, Sock M, Ramsey MG, Netzer FP (2004) Planar vanadium oxide clusters: Two-dimensional evaporation and diffusion on Rh(111). Phys Rev Lett 92 (20):206103

97. Guimond S, Gobke D, Romanyshyn Y, Sturm JM, Naschitzki M, Kuhlenbeck H, Freund HJ (2008) Growth and characterization of ultrathin $\mathrm{V}(2) \mathrm{O}(\mathrm{y})$ (y approximate to 5) films on $\mathrm{Au}(111)$. J Phys Chem $\mathrm{C}$ $112(32): 12363-12373$

98. Guimond S, Sturm JM, Gobke D, Romanyshyn Y, Naschitzki M, Kuhlenbeck H, Freund HJ (2008) Wellordered V2O5(001) thin films on $\mathrm{Au}(111)$ : Growth and thermal stability. J Phys Chem C 112 (31):1183511846

99. Petukhov M, Rizzi GA, Granozzi G (2001) Spectroscopic and structural characterisation of a VOx (x approximate to 1) ultrathin epitaxial film on Pt (111). Thin Solid Films 400 (1-2):154-159

100. Petukhov M, Rizzi GA, Granozzi G (2001) Ultrathin film growth and spectroscopic characterization of VOx $(0.8<=\mathrm{x}<=1.3)$ on Pt(111). Surf Sci 490 (3):376-384

101. Surnev S, Kresse G, Sock M, Ramsey MG, Netzer FP (2001) Surface structures of ultrathin vanadium oxide films on Pd(111). Surf Sci 495 (1-2):91-106

102. Jiang ZQ, Zhou WP, Tan DL, Zhai RS, Bao XH (2004) Evidence for perimeter sites over SmOxmodified Rh(100) surface by CO chemisorption. Surf Sci 565 (2-3):269-278 
103. Kuriyama T, Kunimori K, Nozoye $\mathrm{H}$ (1998) Interaction of CO with the $\mathrm{SmOx} / \mathrm{Ru}(001)$ interface. Surf Sci $402(1-3): 178-181$

104. Zhu JF, Ma YS, Zhuang SX (2009) Exploring the role of samarium in the modification of rhodium catalysts through surface science approach. Surf Sci 603 (10-12):1802-1811

105. Jhang JH, Schaefer A, Cartas W, Epuri S, Baeumer M, Weaver JF (2013) Growth and Partial Reduction of Sm2O3(111) Thin Films on Pt(111): Evidence for the Formation of SmO(100). J Phys Chem C 117

(41):21396-21406

106. Cartas W, Rai R, Sathe A, Schaefer A, Weaver JF (2014) Oxidation of a Tb2O3(111) Thin Film on Pt(111) by Gas-Phase Oxygen Atoms. J Phys Chem C 118 (36):20916-20926

107. Schaefer A, Gevers S, Zielasek V, Schroeder T, Falta J, Wollschlager J, Baumer M (2011)

Photoemission study of praseodymia in its highest oxidation state: The necessity of in situ plasma treatment. J Chem Phys 134 (5):054701

108. Gevers S, Weisemoeller T, Schaefer A, Zielasek V, Baumer M, Wollschlager J (2011) Structure of oxygen-plasma-treated ultrathin praseodymia films on Si(111). Phys Rev B 83 (19):193408

109. Wilkens H, Gevers S, Rohe S, Schaefer A, Baumer M, Zoellner MH, Schroeder T, Wollschlager J (2014) Structural Changes of Ultrathin Cub-PrO2(111)/Si(111) Films Due to Thermally Induced Oxygen Desorption. J Phys Chem C 118 (6):3056-3061 